\title{
The importance of imagination and subjective knowledge: The evolution of art and religion as symbolic representations of feelings, experiences, and beliefs
}

\author{
PLEASE NOTE THAT THIS IS A PRE-PRINT, AND \\ IT SHOULD BE REGARDED AS A WORK IN PROGRESS.
}

\begin{abstract}
We are currently working to incorporate the latest feedback on this article and we envision that substantial changes will be made - this may take a number of months. Please get in touch with Valerie with any questions about this process, or with feedback you'd like to give in the meantime. Thanks!

\section{WE URGE ANY PARTIES INTERESTED IN THIS WORK TO CONTACT THE LEAD AUTHOR (LISTED ABOVE) FOR FURTHER DETAILS OR UPDATES.}

\author{
Valerie van Mulukom ${ }^{*}$, Armin W. Geertz ${ }^{2}$ \\ ${ }^{1}$ Brain, Belief, and Behavior Lab, Centre for Trust, Peace and Social Relations, Coventry University, \\ Coventry, United Kingdom \\ ${ }^{2}$ Religion, Cognition and Culture unit, School of Culture and Society, Aarhus University, Aarhus, \\ Denmark
}

\section{* Correspondence:}

Dr Valerie van Mulukom

ac2492@coventry.ac.uk

Keywords: imagination 1, religion $_{2}, \operatorname{art}_{3}, \operatorname{cognition}_{4}$, culture $_{5}$, meaning 6 , self-transcendence ${ }_{7}$, evolutions. 


\begin{abstract}
Religion and art have been incredibly important in human evolution but, we argue, are often not taken seriously as an important source of knowledge. In this article, we propose that the arts and religions are symbolic systems that capture subjective knowledge, or knowledge about the world that is specific to human experience or the human condition, both concerning the self (existential subjective knowledge) and others (social subjective knowledge). Forms of this knowledge comprise feelings, experiences, and beliefs, which can arise from naturally occurring experiences or can be induced through religious rituals and artistic performances. Subjective knowledge is processed through subjective cognition - experiential or intuitive thinking, narrative processing, and meaningmaking. Individual differences in subjective cognition are proposed to lie in absorption, or the propensity of individuals to allow for a state of the experiential, more porous self, through reduced boundaries of the rational, bounded self. This in turn allows for an immersive focus on sensory inputs, and becoming connected to something bigger than oneself, a state that is especially conducive to providing meaning and new perspectives with regards to the human condition. Together, forms of subjective knowledge make up symbolic systems that feed into overarching subjective knowledge systems, or cultures and worldviews. Thus, religion and art has allowed for subjective knowledge to become represented in symbols and artefacts, which renders the subjective knowledge concrete, memorable and shareable.
\end{abstract}




\section{Introduction}

Homo sapiens are complex creatures consisting of brain, body, emotion, culture, and social relations. Many attempts have been made to delineate our evolution, but there is no easy way to distinguish the causal mechanisms behind this complexity. There is, however, a general consensus that our ability to create symbols and think symbolically - which are central to culture - has driven the expansion of the cortical areas of the brain and, thus, our physiological evolution in a very concrete sense (Terrence W. Deacon, 1997, 2003; Donald, 1993, 2001; Laland, 2017; M. Wilson, 2010). Toolmaking seems to have had a significant role in this evolutionary trajectory (Frey, 2009; A. W. Geertz, 2010, 2013; C. Geertz, 1962/1973; Haidle, 2009, 2012; Hutchins, 2009; Malafouris, 2004, 2008, 2010; Renfrew, 1998; Renfrew, Frith, \& Malafouris, 2009; Spuhler, 1959). Culture, as Joseph Henrich observed, made us smarter (Henrich, 2016).

It is a fact, however, that the hominin line left the shrinking forests long before the significant cortical expansion of Homo erectus brains. Sociologist Jonathan Turner and colleagues argue that a more fundamental change had already occurred in the subcortical regions - specifically the emotional areas - in our immediate ancestor line, the australopithecines (Maryanski, 2013; J. H. Turner, Maryanski, Petersen, \& Geertz, 2018). In tandem with this research, we agree that early hominins were able to attach emotional valence to tokens of symbolic significance important to group cohesiveness. This ability helped solve the social pressures of otherwise loosely organized creatures. Like chimpanzees, these early creatures had a sense of community, but were not hierarchically organized (Maryanski, 1993, 1995, 2013, 2018). But with the emergence of a wider emotional palette, allowing the development of secondary emotions such as shame, love, and awe, the first hominins were able to develop a cohesive symbolic solidarity strong enough to survive in dangerous savannah habitats (J. H. Turner, 2000, 2015, 2019; J. H. Turner \& Maryanski, 2008; J. H. Turner \& Stets, 2009). Indeed, the elicitation of awe by powerful leaders - a complex combination of fear and respect - may have initially developed to help maintain social hierarchy (Keltner \& Haidt, 2003). This solidarity, however, needed to be constantly maintained in order to ensure the continual merging of individual identity with group identity. One of the most important mechanisms for doing this was, evidently, the performance of emotionally arousing collective rituals (J. H. Turner, 2019; J. H. Turner et al., 2018).

In this article, we argue religion and are art are two main symbolic systems associated with such rituals and associated complex emotions and social cohesion. We explain the evolution and functioning of these systems through two broad, complementary forms of cognition, which are both 
required and fundamental to human thinking, life, and evolution. We call these cognitive systems objective cognition and subjective cognition, and suggest that they explain objective and subjective reality respectively (van Mulukom \& de Wet, forthcoming).

We suggest that objective cognition and knowledge - the accurate representation of empirical phenomena in the physical world - was no doubt incredibly important for human survival. However, subjective cognition and knowledge - the understanding of human experience, both in terms of the self (existential subjective knowledge) and others (social subjective knowledge) is what allowed humans to thrive and survive, supported by cultural evolution. A crude distinction might be to suggest that science explains how, religion (or art) explains why (Rutjens \& Preston, 2020). We argue that the creation of the arts and religion - as particularly important human cultural phenomena allowed for subjective knowledge to become represented in symbols and artefacts, the latter serving as material anchors. This rendered the subjective knowledge concrete, memorable and importantly, shareable. With this model, we hope to demonstrate the significance of subjective cognition and that art and religion are not symbolic systems for making things "look good" and explaining the world in "fairy tales", but instead are important parts of what makes humans human (even if they are nonartistic and non-religious themselves), and that art and religion have done so for thousands of years.

The sciences, whether empirical, physical studies, mathematics, or even philosophy, consist of an established base (evidence, axioms, premises) and conclusions (theories, theorems, and conclusions). The chain of reasoning, the effort to go from base to terminus, is guided by sequential logic or a set of rules of reasoning. It has been suggested that there are no obvious parallels to this in the arts (Graham, 2005), but in our model, we will suggest a variety of forms of subjective knowledge (i.e., feelings, experiences, beliefs) that make up the base, and a variety of symbols that make up the conclusions (i.e., artistic and religious symbols), with a number of subjective cognitive processes to get from base to conclusion (i.e., experiential thinking, narrative thought, and meaning making), see Figure 1. 


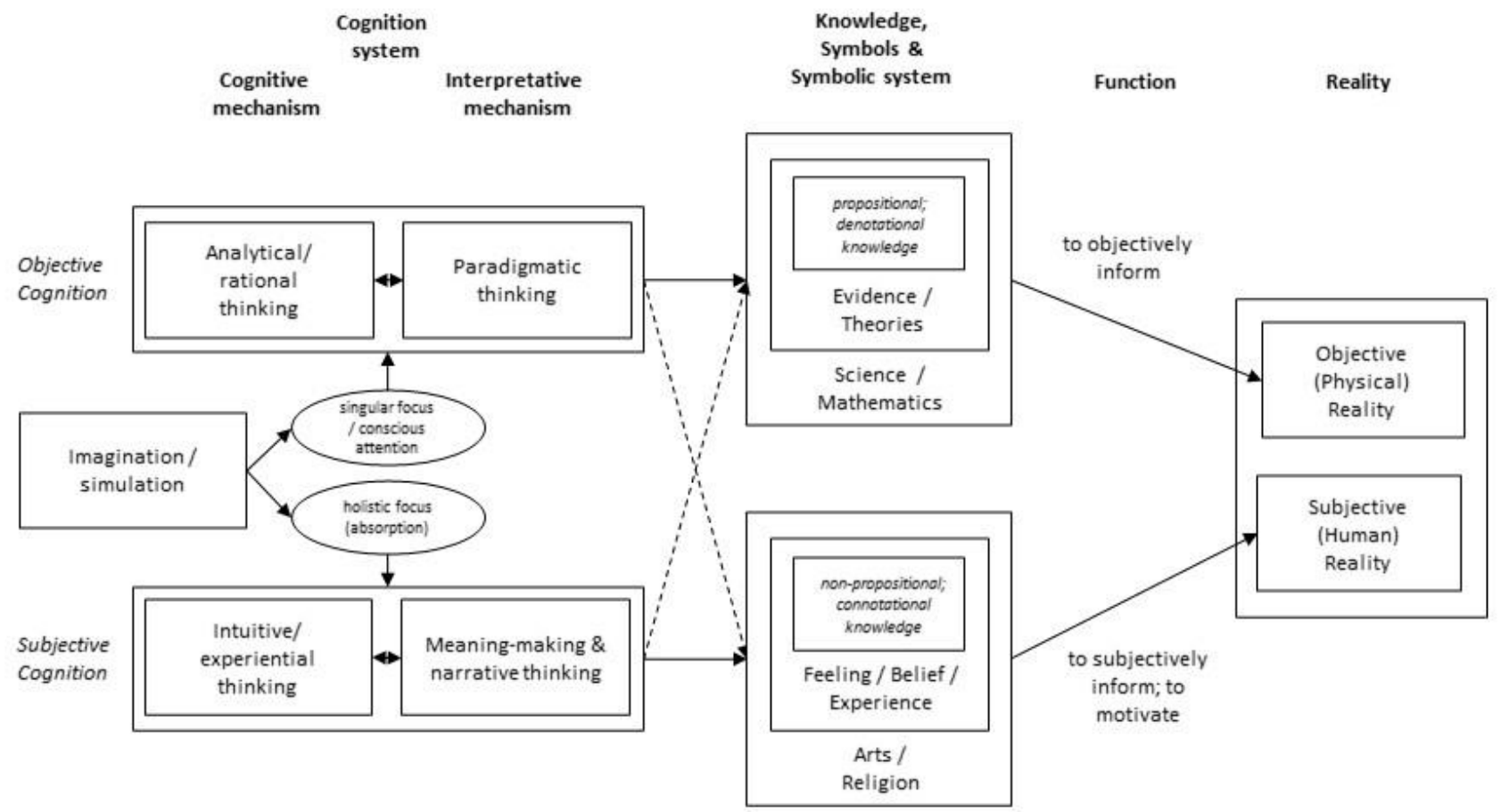

Figure 1. Model of how objective and subjective cognition are used to make sense of reality

More specifically, we argue that emotions (feelings with high arousal) signify salience as well as motivational valence - thus directing attention and motivating behaviors or intentions. Emotions take place within experiences, which can be naturally occurring or intentionally created through ritualistic events and performances. The transcendental state (e.g., awe), produced in both artistic and religious experiences and rituals, imbues (artistic and religious) experiences with extraordinary meaning. This state importantly reduces regular boundaries of the self, allowing a change from the rational to experiential self, and is saturated with high-arousal emotion (chemically supported by dopamine and endorphins). We suggest that experiences full of emotion can become the basis for beliefs. The feelings, experiences, and beliefs are processed through intuitive thinking, narrative thought, and meaning-making (which together make up subjective cognition). People differ in their subjective cognition according to individual differences in traits and predispositions like absorption, among others. The emotions associated with experiences become symbols for these experiences through a dopaminergic process of 'stamping in' the emotions in memory. The symbols can be internal memories (i.e., thoughts), or external, in the form of artistic or religious artefacts (e.g., whether material or performative, etc.). The symbols together form a symbolic system (e.g., a form of art or 
religion), which in turn feeds into overarching structures of subjective knowledge systems, or culture and worldviews, which meet existential and social needs, see Figure 2.

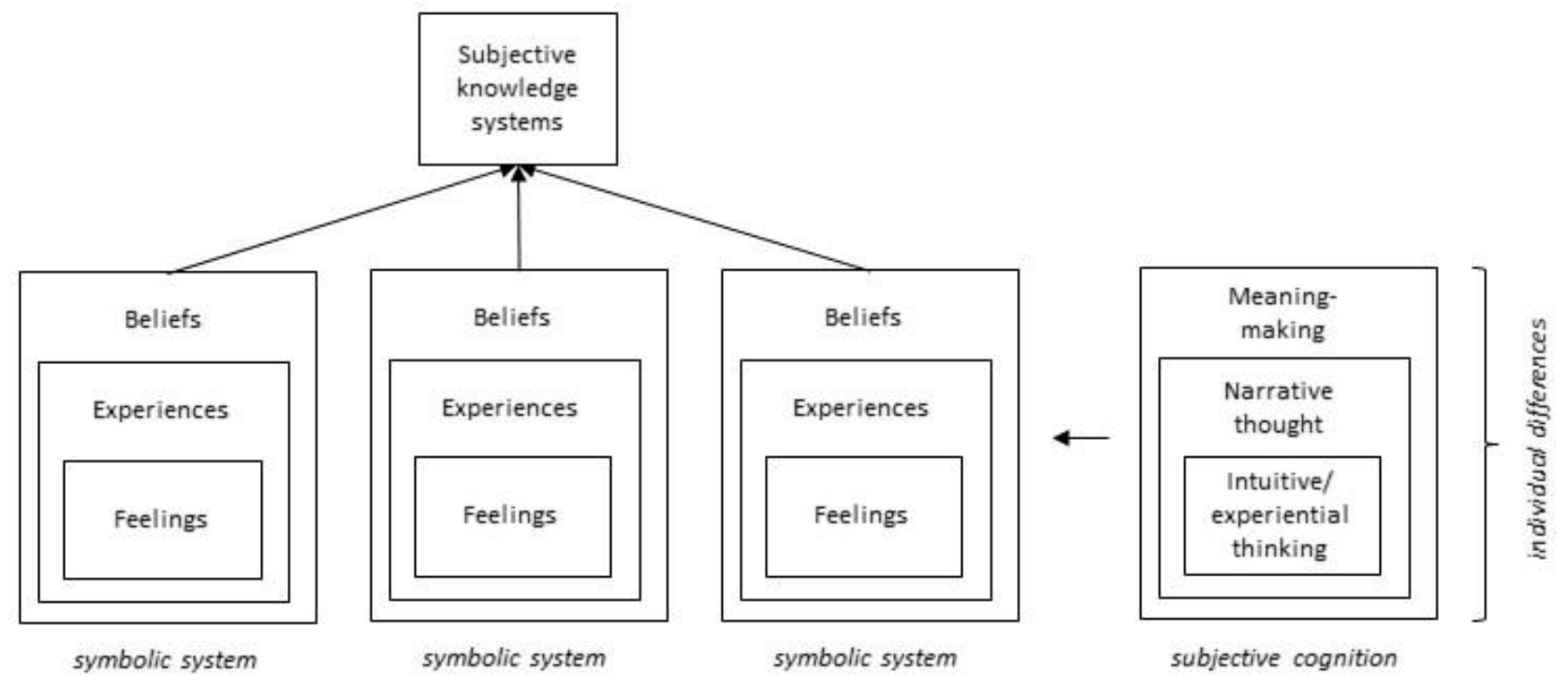

Figure 2. Forms of subjective knowledge within symbolic systems and associated forms of subjective cognition

We will first discuss key concepts, starting with subjective knowledge systems, followed by what we mean by subjective knowledge. A discussion of the forms of subjective knowledge will then be followed by the symbolic systems by which they are captured, before moving to subjective cognition, the processes by which subjective knowledge (and its symbols) is created and understood, and individual differences related to this cognition.

\section{Subjective knowledge systems}

In order to disentangle the myriad relations between symbolic systems, culture, art, religion and worldviews, we draw on the insights of earlier sociologists, anthropologists, and philosophers. Such insights are now finding support in current cognitive, neuropsychological, and experimental psychology and studies of religion. We will, however, restrict ourselves to brief discussions of key concepts before moving on to more detailed discussions of subjective knowledge.

There is no generally accepted definition of the term "culture". Baldwin et al. (2006), in their content analysis of 313 definitions from a wide variety of scholars in the humanities and social sciences, abandoned the idea of providing a synthetic definition (A. W. Geertz, in press). We draw on anthropologist Clifford Geertz's semiotic understanding of culture as "webs of significance" (C. Geertz, 1973, p. 5). These webs of significance are symbols that can be any "object, act, event, 
quality, or relation" that serves "as a vehicle for a conception" (C. Geertz, 1966/1973, p. 91). Cultural patterns, i.e., symbolic systems, provide models for and models of social and psychological reality (C. Geertz, 1966/1973, p. 93); in other words, models to show how to behave, and models to show how the world is. Geertz argues that the transposability "of models for and models of [the world] which symbolic formulation makes possible is the distinctive characteristic of our mentality" (C. Geertz, 1966/1973, p. 94). This transposability is especially evident in religious symbols and symbol systems.

For Geertz, art and religion, as well as much else, are cultural systems. Religion, he defines as: "(1) a system of symbols which acts to (2) establish powerful, pervasive, and long-lasting moods and motivations in men by (3) formulating conceptions of a general order of existence and (4) clothing these conceptions with such an aura of factuality that (5) the moods and motivations seem uniquely realistic" (C. Geertz, 1966/1973, p. 90). ${ }^{1}$ Here, we argue that this definition can also be readily applied to other symbolic systems, such as those resulting from the arts, especially given the lack of reference to belief in supernatural beings.

This definition is useful here because it points to Geertz' key concepts of "ethos" and "worldview". A people's ethos is "the tone, character, and quality of their life, its moral and aesthetic style and mood; it is the underlying attitude toward themselves and their world that life reflects" (C. Geertz, 1957/1973, p. 127). Ethos is basically the emotional underpinnings of cultural systems. A worldview is "their picture of the way things in sheer actuality are, their concept of nature, of self, of society. It contains their most comprehensive ideas of order" (C. Geertz, 1957/1973, p. 127), in other words, more or less intellectually formulated ideas about the world and reality. In the contexts of religious ritual, ethos and worldview are transposed and, thus, reinforce one another, transforming participants' sense of reality and belonging (C. Geertz, 1966/1973, p. 112). This transposability, as will become evident below, occurs through the emotional effervescence generated by collective rituals. Such rituals stimulate symbolically and culturally mediated feelings about the rightness of being an individual member of a particular ethnic, tribal or any other social group.

Long before Geertz, sociologist Émile Durkheim emphasized the social and psychological significance of religious rituals. Durkheim posited that the human realization of invisible, anonymous forces outside of themselves and their influence on human society are conceived through tokens or

\footnotetext{
${ }^{1}$ There is nothing peculiar to "religion" in this definition as it does not point to what we most often find in the religions of the world, namely, ideas about supernatural and other-than-human beings. But, as with the term culture, there is no generally accepted definition of the term "religion" either (Smith, 1998; Geertz, 1999; Jensen, 1999; Platvoet and Molendijk, 1999; Jensen, 2017).
} 


\section{PREPRINT}

symbols of totemic animals and vegetal beings. This, what he calls the "totemic principle," is at once a physical force and a moral power that provides psychic pressure on individual consciousness (É. Durkheim, 1912/1995, p. 192). This principle consists of a social pressure that makes itself felt through mental channels (É. Durkheim, 1912/1995, p. 211) and connects individuals to the collective body. It transfigures them, not only, but especially, in the context of religious ritual. Through the emotional stimulation of such rituals, a moral society is continuously renewed and fused with the forces that influence them. This happens by the emotional effervescence resulting from such rituals. The symbol and the idea of the greater thing or being behind it are united during the ritual (É. Durkheim, 1912/1995, pp. 221-222). Durkheim distinguishes between collective effervescence, as the emotional charging force, on the one hand, and what he calls "dynamogénique", which generates social and psychological identity within the framework of religious ideals and practices, on the other hand. As he and Marcel Mauss noted, "it gives the individual forces that allow him to transcend himself, to raise himself above his nature and to master it" (Mauss \& Durkheim, 1913; Miller, 2005).

A contemporary of Clifford Geertz, anthropologist Victor Turner, was also a symbolic anthropologist, but unlike Geertz, he was interested in the performative aspects of ritual, thus helping found processual anthropology (V. Turner, 1969). Turner's central interest was the "social drama", understood as encompassing a fourfold process in which (1) the social order is breached, (2) thus initiating a crisis, (3) which must be confronted by redressive procedures (4) in order to re-establish the social order, or, in case of irreparable damage, to recognize a schism (V. W. Turner, 1968). Redressive processes could be through political, judicial, and/or ritual processes.

In drawing on Arnold van Gennep's analysis of rites of passage as consisting of three stages: rites of separation, margin, and reaggregation (van Gennep, 1909/1960), Turner focussed on the middle phase, which van Gennep also called the "liminal" phase (from Latin limen, "threshold"), that is, the "betwixt-and-between" moment in religious rituals, during which participants are physically and symbolically outside of the normal social order (V. Turner, 1967; 1985a, p. 292). During this phase, the participants are simultaneously confronted with the sacred symbols of their society visually with objects, masks, costumes, and by performances that enact and express these symbols, and by formal and informal instructions (myths, riddles, teachings). They are also subjected to the ludic deconstruction and recombination of cultural models, and, indeed are in a state of "antistructure", by which social and structural relationships are mirrored and, ultimately, confirmed. They are confronted by what Turner called the "root paradigms" of their culture (V. Turner, 1985b, p. 167). Participants become transformed into a transcendent dimension, which produces a sense of collectivity (termed communitas). In this phase, participants come away from the ritual with a 
renewed sense of identity and purpose. Ritual is, for Turner, a transformative performance that reveals the values and categories of a cultural system, but also, not unlike Durkheim, the "generative source of culture and structure" (V. Turner, 1985b, p. 171).

Stage drama, Turner argues, is the inheritor of preindustrial ritual dramas, and they have similar effects in complex societies: Not only in theatres but also in the cultural dramas of carnivals, movies, television shows, and literature. Stage dramas are often metacommentaries on society and the social order, similar to the ludic rituals in the liminal phase of preindustrial ritual processes. In complex societies, the same threefold structure, noted by van Gennep, is observed in for example theatre performances. The middle phase Turner termed the "liminoid" during which the sacredness of preindustrial liminality is greatly reduced, but still somewhat present, in these "dramas of life" (V. Turner, 1985a, pp. 296-301). All societies, he argues, need to restabilize and "actually produce" the cosmos through such performances whether religious or secular (V. Turner, 1985a, p. 301).

Which brings us back to art and aesthetics. As mentioned, Clifford Geertz considered art and religion, as well as much else, to be cultural systems. It is a way of being-in-the-world as expressed through "aesthetic force" (C. Geertz, 1976/1983, p. 97). "The means of an art," Geertz argues, "and the feeling for life that animates it are inseparable" (C. Geertz, 1976/1983, p. 98). In other words, art is a sensibility that is essentially "a collective formation ... as wide as social existence and as deep" (C. Geertz, 1976/1983, p. 99) which serves, like any other sign system, as vehicles of meaning. Art makes these meaning systems visible, audible, and tactible (C. Geertz, 1976/1983, pp. 118-119), even though such systems can vary from culture to culture. They are conceptions that people have "about the way things are" (C. Geertz, 1976/1983, p. 120).

Sociologists Peter Berger and Thomas Luckmann in their treatise on the social construction of reality argue that societies provide meaningful existence for their members through "nomic constructions" or meaningful symbolic universes (Berger \& Luckmann, 1966, p. 119), in other words, worldviews. These symbolic systems consist of signs as an index of subjective meanings that have been objectified and, thus, become objects of internalization for members of a society through socialization in everyday life. Social order exists as a product of human activity that is institutionalized, legitimized, maintained, and transmitted throughout society and transgenerationally (Berger \& Luckmann, 1966, p. 70). Thus, individuals are, as Geertz noted, caught in webs of significance that give meaning, subjective plausibility, and cognitive validity. The symbolic universe encompasses all of society and every individual in it (Berger \& Luckmann, 1966, p. 114). The symbolic universe, Berger and Luckmann argue, quite simply "puts everything in its right place" (Berger \& Luckmann, 1966, p. 116). 
Humans are caught up in webs of significance, as Clifford Geertz would have it, or cognitive webs of feelings, memories, and knowledge, as Merlin Donald would have it, which produce cognitive governance systems that are the bread and butter of socialization (Donald, 2001, p. 255). We as a species are the result of a collective process because of the dramatic expansion of external memory banks, symbolic systems, and an enormous range of communication possibilities (Donald, 2001, p. 326).

\section{Subjective knowledge}

\subsection{Objective versus subjective knowledge}

Examining what constitutes knowledge or information or how we come to know it is captured by epistemology, the philosophy of knowledge. There are several broad paradigms within epistemology. Here, we will highlight two: In the positivist paradigm, knowledge can be discovered and verified through observations or measurements of the phenomena, but the object of study exists independent of the examiners. In the naturalist or constructivist view, knowledge is established through the meanings attached to the examined phenomena, meaning that the interactions with the object of study are important to the knowledge, which is context and time dependent (Krauss, 2005). This is not to say that these types of information cannot coexist. These types of knowledge have been called objective and subjective knowledge, respectively (Dervin, 1977). Dervin proposes that objective knowledge describes reality and its innate structure or patterns ('external reality'), whereas subjective knowledge comprises ideas that describe structures imputed to reality by people ('internal reality') (Dervin, 1977).

Here, our definition of objective knowledge will refer to knowledge of observable phenomena, in line with the positivist paradigm, though to some extent we will concede that even objective knowledge is also imputed to reality by people as it is knowledge which is the result of human sensory organs and that exists in imagination (Chalmers, 1994; Putnam, 1992; Searle, 1998). Objective knowledge is thus the knowledge that is empirically derived from observable phenomena in the natural world (but distinct from Platonic ideas - we will not make assumptions about the 'true' nature of reality). Subjective knowledge as defined here will refer to knowledge about the world that is specific to human experience (or the human condition), in line with the naturalist/constructivist' view.

Objective cognition factually informs humans about physical reality. Clearly, this system is greatly important for human thriving and survival: Having an as accurate representation of reality as possible (within the range of sensory abilities available to the creature) allows for appropriate 
behavior. For example, identifying non-poisonous berries from poisonous berries, which may require fine detail perception and factual knowledge about the berries' effects, before eating them is crucial for survival. In fact, it is hard to think of scenarios where having an accurate representation and factual understanding of reality is not beneficial for thriving and survival, from avoiding poisonous berries to accepting vaccinations (Henrich, 2016). Indeed, it should be understood that it is not the case that either objective or subjective knowledge is superior or indeed pivotal for human lives, but that they are complementary to each other, with each their own principles and aims. While objective knowledge factually explains empirical events in physical reality, subjective knowledge is geared more specifically towards (relative) human experience, in particular identity and social relations, and attempts to inspire and motivate, as well as to inform, through intuitive, narrative knowledge rather than empirical, rational facts.

Human experience is importantly about the self as much as others. Durkheim has suggested that humans are Homo Duplex: "Indeed, far from us being straightforward, our internal life has something like a double centre of gravity. On the one hand there is our individuality, and, more especially, our body that is its foundation; on the other, everything that, within us, expresses something other than ourselves." (E. Durkheim, 2005, p. 37). Similarly, we suggest that knowledge about the human experience encompasses knowledge about the self on the one hand (including identity and one's place in the world; existential subjective knowledge), and others on the other hand (including social relations; social subjective knowledge). Both types of subjective knowledge are unified in that they are typically non-rational, closely reliant on emotion to guide us, represented in symbolic systems, and specific to human experience. They are motivated understanding of the world. Importantly, we argue that both serve important roles; we do not presume that the existential or social function takes precedence (van Mulukom \& Clasen, 2021).

Facts about the world can be empirically measured and observed, but feelings, experiences, and beliefs are relative to the subject ('owner') of these ideas, even if they can be shared. A problem of the idea of subjective knowledge is thus that it is relative in some sense, and since each of us experiences from our own point of view, each of us therefore experiences a different reality (Krauss, 2005). Nonetheless, we do not want to suggest a postmodern approach here, nor will we make claims about the ontology of reality, or to what extent we can truly know reality. Instead, we postulate that humans empirically perceive (both natural and human-specific) reality in a relatively uniform way: The majority of humans have eyes, ears, noses, mouths, and hands (e.g., sensory apparatus), and similar brains (e.g., sensory interpretative apparatus). Therefore, we suggest that broad but useful generalizations about human thought and experience can be made. Even if individual understandings 
will differ minimally, we argue that in cultures and worldviews, a common understanding prevails and becomes anchored through symbolic systems.

A central cognitive apparatus through which we perceive the world is imagination. Here, we will define imagination as the generation of persons, locations, and objects in the mind's eye (van Mulukom, 2019), which often may present itself in mental imagery, though this need not be the case, as in individuals with aphantasia. We have argued elsewhere (van Mulukom \& Clasen, 2021) that the main mechanism behind imagination is to engage in mental simulation (cf., Barsalou, 2009; Shanton \& Goldman, 2010). As such, it is clear that imagination supports both objective and subjective cognition: Humans use simulation and higher thought to represent, comprehend, and engage with the world around them. A pivotal difference might be how imagination is used: a singular focus combined with conscious attention might best serve objective cognition (Evans, 2008; Stanovich \& West, 2000), whereas a holistic focus combined with absorption (a form of hyper attention without conscious intervention) might best serve subjective cognition. Here we do not aim to explain the underlying mechanisms of objective cognition, but will return to holistic focus in section 6 Individual differences in subjective cognition.

\subsection{Subjective knowledge in the arts and religion}

Human culture (including but not restricted to art and religion) is the most straightforward exemplification of subjective knowledge of reality: subjective cognition together with the capacity for imagination allows us to endow entities in the physical world (objects, persons, but also relationships) with culture-specific properties, such as certain roles or functions, with associated rights, duties, and activities (Searle, 1995), which are not empirically observable in the physical world, but which exist in our 'imagination'.

Here we focus on subjective knowledge as mobilized by the arts and religion. We suggest that at the core of religious experiences is a process that is much like artistic experiences, with the added element of a religious or spiritual interpretative framework or narrative. This is not to be taken lightly: We suggest, in line with our previous work, that narratives - as part of both existential and social subjective knowledge - are guiding principles coloring our everyday perceptions and experiences (A. W. Geertz, 2011; van Mulukom \& de Wet, forthcoming; van Mulukom \& Lang, 2021).

The idea that the arts have a significant cognitive contribution is a central tenet of aesthetic cognitivism (Graham, 2005). This branch of philosophy argues that the arts are not just for diversion (pleasure, entertainment) or decoration (beauty, enjoyment), but provide understanding. This is not to 
suggest that all art does this, just like not all scientific hypotheses provide significantly enhance our understandings. 'Understanding' should be taken here not as a type of belief, but as a cognitive achievement not reliant on the knowledge of verifiable facts (Baumberger, 2014). It is holistic (cannot be broken into discrete bits), is gradual (there are degrees of understanding, rather than knowing something or not), and varies in breadth, depth, significance and accuracy (Baumberger, 2014).

It is one of the strengths of works of art that they are not constrained by verifiable facts, but that they exist in imagination. That is not to say that the sciences do not have grounds in imagination, but that the ontological status of subjective knowledge - existence in imagination - reflects the lack of a direct empirical counterpart of the work of art in the world: its connotational rather than denotational status. If it is not accuracy of representation that is the (main) function of the $\operatorname{arts}^{2}$, then how does it convey its understanding? First, we need to understand what cognitive advancement is. Baumberger argues that if we take cognitive advancement to just be growth of (verifiable, propositional) knowledge, then learning trivial or irrelevant facts would constitute cognitive advancement, even if the learning of these facts are irrelevant. Instead, we may be better served here with an epistemology of understanding, which suggests that cognitive progress can be achieved through a number of ways which do not provide factual propositional information and which are directly relevant to the arts and religion: the cognitive advancements of understanding are (1) to enable us to grasp connections between what we already believe; (2) to provide new cognitive categories and perspectives; (3) to raise important questions; (4) to provide knowledge of what it is like to have certain experiences or emotions; (5) to develop elaborate thought experiments; and (6) to enhance our cognitive abilities (Baumberger, 2014).

Providing a new perspective may be the main cognitive contribution of the arts; rather than directing the mind through a progression of thought such as in scientific experiments, historical narratives, or philosophical arguments (Graham, 2005). Indeed, seeing the world 'anew' as a result of experiencing art or religion is a common idea, as French-Cuban-American author Anaïs Nin wrote: "It is the function of art to renew our perception. What we are familiar with we cease to see. The writer shakes up the familiar scene, and, as if by magic, we see a new meaning in it." (Nin, 1968, p. 25). Another, similar cognitive advancement that artistic and religious experiences can provide is that they can result in experiencers asking new questions. In this case, progress can be achieved through

\footnotetext{
${ }^{2}$ Though the evaluation of the accuracy or faithfulness of descriptions and representations is often important to an aesthetic evaluation of art: works of art often do not work if there is not sufficient similarity with the real world (Gaut, 2004).
} 
clarification rather than solution of problems. Besides, sometimes the questions do not have a single, true answer, such as moral questions. Fiction - whether books or films or literature - appears particularly apt at inducing such questions. The British dystopian science fiction anthology television series Black Mirror, created by Charlie Brooker, is a prime example of how complex moral situations can be presented from various perspectives. Religion is of course well-known for its involvement in moral questions. It may appear that religion provides clear answers to moral questions, but a large literature of theological books just within Christianity suggests otherwise (Greene, 2013).

Cognitive progress can also be made when an artwork or experience allows the experiencer to become directly acquainted with certain sensory or emotional qualities, which provide us with knowledge of what it is like to have certain emotions or experiences (e.g., to be in certain situations). Works of art can supply imaginative apprehension of experience whether visual, tactile, emotional, or mental. The value of this apprehension may be directly related to how deficient or able we ourselves are in those regards (see section 6 Individual differences in subjective cognition). By making these aspects salient, art becomes a source of (new) understanding, beyond our own, previous experiences. Gaining new understandings of experiences seems very particular however, and that particularity of works of art appears to be counter general understanding. It need not be, though: for example, while indigenous knowledge, or 'traditional ecological knowledge', is embodied and particular, and not theoretical and universal, it can be more appropriate than scientific knowledge in certain situations, because of its motivational role, its deep emotional links to specific objects and places (Asma, forthcoming). Sometimes cognitive process is not made by learning more facts, but by developing new connections between ideas (including new hierarchies) and new categories, in particular within a domain appropriate to our cognitive goal (Baumberger, 2014). Thus, domain particularity is not necessarily a weak aspect of knowledge or understanding.

\subsection{Use of subjective knowledge}

Whether objective or subjective knowledge may be considered most appropriate depends on the context: for example, an epistemology of the natural world may be better served by objective thought, whereas an epistemology of the existential and social world may be best served by subjective thought. The epistemology of the existential and social world consist of meanings, categories of which can be summarized through what have been called the 'big questions' (Taves, Asprem, \& Ihm, 2018), and which together form worldviews (Koltko-Rivera, 2004; van Mulukom et al., 2021). 
There are, however, plenty of misunderstandings about the co-existence of these types of thinking, especially in the Western world. For example, someone who claims that the Bible is 'wrong' because it is factually incorrect (e.g., walking on water is not possible) or because miracles cannot be scientifically tested, fundamentally misunderstands the subjective truth of the (sacred) narrative and its functions. An example of how objective and subjective thought each serve their own functions, is the report of the explanations of a termite-infested roof collapsing by the Azande (an ethnic group of North Central Africa) by anthropologist E. E. Evans-Pritchard: When the roof of a granary collapses, it is understood by the Azande that the termites were the proximate, immediate cause of the incident. This objective knowledge can be observed and verified empirically. However, it is also understood by the Azande that the ultimate, distal cause of roof collapsing is witchcraft, which explains why it happened at a particular time, with certain people in the building. Thus, the subjective knowledge is context and time dependent, and importantly, socially relevant (EvansPritchard, 1937).

Similarly, anthropologist Maurice Bloch suggests that there is a transactional and transcendental element to human interactions: in an objective manner, we act towards other human beings as they appear to us and our sense at a particular point in time (transactional interaction), but we also take into account subjective knowledge about the individual - for example, whether they are a tribe's chief or simple member (transcendental interaction). Such cultural 'status assignments' exist only in imagination - they are not empirically observable in the physical world (van Mulukom, 2019) - but have real-life consequences, and can confer evolutionary benefits (van Mulukom, 2020), such as in the form of greater resources for the individual, but also increased group cohesion through the maintenance of hierarchies, etc. Religious beliefs and credibility displays are a form of such cultural assignments (Stark, 2009).

Subjective knowledge does not just affect how we interpret the world however, it also affects how we perceive it (A. W. Geertz, 2013; Schjoedt et al., 2013b; van Mulukom, 2020; van Mulukom $\&$ Lang, 2021). Predictive processing frameworks suggest that the brain makes sense of the world through continuously generating predictive models of the world, which are based on previous experience, and these are compared to sensory input (Bar, 2009; Friston \& Kiebel, 2009). When mismatches between predictions and sensory input are detected, predictions are updated accordingly. Importantly, the predictive models or priors also influence what is perceived, in particular when sensory information is degraded or ambiguous (e.g., in dark rooms or opaque contexts such as certain religious rituals). In these cases, internal models of the world dominate the predictions, and signal may be experienced even if there is only noise. This has led certain participants - especially those 
scoring high on absorption or spirituality - to perceive a sensed presence or have mystical experiences in studies that have used a placebo 'god helmet' (a helmet which was described to participants as being able to induce mystical experiences through electromagnetic stimulation to the brain, but which in reality conducted no electrical current)(Andersen, Schjoedt, Nielbo, \& Sørensen, 2014; Maij \& van Elk, 2018; Michiel van Elk, 2014).

Thus, there is a two-way interaction between top-down and bottom-up models in how brains perceive and interpret the world, and subjective knowledge are an important part of that process. In other words: "[...] we structure (and repeatedly restructure) the social and material worlds that slowly but surely structure us" (Clark, 2015, p. 300). This research also emphasizes the importance of taking into account the embodied nature of human thought: imagination is "an interactive and embodied process that cannot adequately be understood without considering an individual's personal history and previous experiences as well as emotions and feelings" (Ovsepyan, 2019, p. 92); these processes shape human experience and the production of meaning.

\section{Forms of subjective knowledge}

In the following section, we will discuss the forms of subjective knowledge and their functions: (4.1) feelings which contribute to salience and motivation, and a noetic sense of realness, (4.2) experiences, such as during religious rituals and the experience of self-transcendence and awe, and (4.3) belief, and how they together form (4.4) symbols in symbolic systems like art forms and religion.

\subsection{Feelings}

\subsubsection{Salience and motivation}

Emotions are affective states that differ in arousal (from low to high) and appraisal valence (unpleasant/aversive to pleasant/rewarding) (Barrett, 2017). These interoceptive experiences are interpretations of salience signals, bodily signals which tell the individual to pay attention to something. Emotions are culture-specific labels to these interpretations of bodily signals. Thus, cultures determine which emotional concepts come to exist (e.g., through language). By identifying emotions as signals of salience, brain regions preoccupied with emotion, such as amygdala, may be called salience detectors (Cunningham \& Brosch, 2012). It comes as no surprise then, that the amygdala reliably and significantly activates to process fear, which is a highly salient and significant emotion. 
Emotions are associated with the memories in the brain through the process of associative learning, supported by dopamine (Bromberg-Martin, Matsumoto, \& Hikosaka, 2010). The brain processes some stimuli as intrinsically rewarding (e.g., a sweet taste) or intrinsically aversive (e.g., a very bitter taste); such unlearned stimuli are primary reinforcers (Deeley, 2004; Rolls, 2000). When encountering neutral stimuli, the brain may associate these stimuli to primary reinforcers, resulting in these stimuli becoming encoded as secondary reinforcers themselves, by the amygdala and orbitofrontal cortex (Davidson \& Irwin, 1999; LaBar \& Cabeza, 2006). Thus, stimuli can induce salience signals directly (primary enforcers) or indirectly (secondary enforcers). Such motivational importance is attached to otherwise neutral environmental stimuli through the 'stamping in' of memories, supported by dopamine release (Wise, 2004).

The 'motivational salience' hypothesis of dopamine suggests that the dopaminergic system attributes salience to stimuli (whether environmental, events, or thoughts), which then come to grab attention, influence intentions, and drive action, due to the association with aversion and reward (Bromberg-Martin et al., 2010). Moreover, it has been suggested that an overload of dopamine, as seen in patients with schizophrenia, leads to 'aberrant salience' (Kapur, 2003): external and internal stimuli are assigned inappropriate salience and motivational significance.

Thus, affective states that we call emotions signal salience through arousal (low arousal identifying little salience, high arousal identifying a lot of salience) and motivate behavior through their valence (aversive stimuli indicate avoidance, rewarding stimuli indicate approach) ${ }^{3}$.

\subsubsection{Noetic sense of realness}

An additional effect of dopamine is the assignment of meaning (and finding patterns). Indeed, it is the emotional and sensory overload as well as an overload of feelings of meaning - importantly regardless of the individual being able to pin down what this meaning is - that has been related to impending onset of psychosis in schizophrenia (Mishara \& Fusar-Poli, 2013). Thus, an onslaught of dopamine might create the psychological state that is particularly open to detecting new meaning(s) (i.e., an exploratory style of attention), and that leads the individual to considering the situation to be significant, which may facilitate changes in belief and behavior, for better (e.g., when purposively induced through ritual) or for worse (e.g., in case of psychosis). Overstimulation of dopamine can also lead to the sense that reality feels so meaningful that it feels more 'real' or authentic than usual

\footnotetext{
${ }^{3}$ Note that we avoid language of 'positive' or 'negative' emotions: certain emotions which in common parlance may be considered negative (e.g., anger or sadness) can motivate both avoidant and approaching behaviors.
} 
reality. For example, as in MDMA users, MDMA positively alters the users' evaluation of the self through increasing feelings of authenticity (Baggott et al., 2016).

The sense that certain experiences are 'real' or involve contact with a higher, truer reality than that of ordinary experience has been called their noetic quality (Hood Jr, 1975; Yaden, Le Nguyen, et al., 2017). A noetic sense of realness is suggested to occur in religious and spiritual experiences in particular, which as a result feel more real than profane reality, providing insight into the way things "really are" (Yaden, Le Nguyen, et al., 2017). Yaden and colleagues found that, when individuals are directly asked, religious, spiritual, and mystical experiences are consistently perceived as more real than one's usual sense of reality (Yaden, Le Nguyen, et al., 2017). Neuropsychiatrist Quinton Deeley has argued that this sense of realness, "the really real", as Clifford Geertz phrased it (C. Geertz, 1966/1973), combining human moods and motivations with conceptions of the world, is produced by a sensory route and a semantic route, both of which activate the mesolimbic dopamine system, among other cognitive-emotional processes, by which "religious ideas are turned into convictions" (Deeley, 2004).

\subsection{Experiences}

Events or moments which are loaded with emotion, in particular of high arousal, constitute experiences, which with sufficiently high levels of meaning can become transformative experiences. Experiences are occurrences when an emotion becomes linked to the internal or external stimuli in a memory (e.g., natural setting). Such a memory of a stimulus saturated with certain affective states can also be purposely created (e.g., ritual settings). Since in memories of ritual or artistic performance, the memory of experience becomes associated with emotions, they become secondary reinforcers (and symbolic representations), evoking similar emotional and motivational responses when the memory is recalled as when the event was experienced. Religious and artistic artefacts can be considered an additional step of abstraction: the artefact is a symbol for an experience, but the experience may not have been had by the current witness of the religious or artistic artefact. Here we will discuss religious rituals, and experiences of self-transcendence and awe.

\subsubsection{Religious rituals}

Religious rituals are a common source of the intentional induction of significant experiences, and have been for millennia. Possibly first exhibited in proto-rituals and later in shamanic rituals, early religious rituals likely involved a number of mechanisms such as excessive physical movement (drumming and dancing until exhaustion), consuming psychoactive substances, sleep deprivation, and fasting, which induce altered states of consciousness (ASC), such as hallucinations, hypnotic 


\section{PREPRINT}

states, trance states, and meditation (Ember \& Carolus, 2017; A. W. Geertz, 2010). Such rituals were initially reserved for specifically trained and induced practitioners, shamans, or other magicoreligious healers (Andresen \& Forman, 2000; Cardeña \& Winkelman, 2011; Dubois, 2009; Francfort, Hamayon, \& Bahn, 2001; Heinze, 1991; Siikala, 1987; Winkelman, 1992), and dissociational stateinducing rituals still occur in many societies today (Bourguignon, 1968; Cardeña \& Winkelman, 2011), though with different degrees of social validity and acceptance (Bartlett, 1988; Castillo, 1994a, 1994b; Chapin, 2008; Goodman, 1974; Hayes, 2006; Lewis, 2003; Suryani \& Jensen, 1995; Winkelman, 1986).

But religious rituals do not just produce individual effects. As mentioned previously, rituals have long been known to anthropologists to generate intense feelings of social togetherness and belonging (É. Durkheim, 1912/1995; V. Turner, 1969). While there is no definite answer to the exact mechanisms that induce such social states yet, there are a number of candidates which frequently occur as ritual components, such as group synchronized movement including dance (Fischer \& Kruekaew, 2019; Tarr, Launay, Cohen, \& Dunbar, 2015; Tarr, Launay, \& Dunbar, 2016), music making (Becker, 2004; Brown \& Volgsten, 2006; Brust, 2007; Pearce, Launay, \& Dunbar, 2015; Pearce et al., 2016; Savage et al., 2020), and extreme rituals (Fischer \& Xygalatas, 2014; Hobson, Schroeder, Risen, Xygalatas, \& Inzlicht, 2017; Konvalinka et al., 2011; Schjoedt \& Jensen, 2018; Schjoedt et al., 2013a; Xygalatas, 2008, 2014; Xygalatas, Konvalinka, Roepstorff, \& Bulbulia, 2011). This suite of behaviors can be powerful enough to alter our state of consciousness, and in so doing, take a group far away from its conventional realms of normality (or the profane), and into the surreal and sacred. As noted by Victor Turner, this liminal state gives group members an opportunity to transcend the boundaries between self and group. Indeed, the ritual components produce a strong connection with others (Frecska \& Kulcsar, 1989; Konvalinka et al., 2011; Power, 2018), though this may be extended to connection with non-physical forces or experiences of self-transcendence too.

In a series of fieldwork and laboratory studies, Charles and colleagues have demonstrated that attending a religious ritual together increases social bonding (Charles, Farias, et al., 2020; Charles, van Mulukom, Brown, et al., 2020; Charles, van Mulukom, Farias, et al., 2020; Charles et al., manuscript). Importantly, increases in social bonding after rituals were predicted by increases in positive affect and feelings of connectedness to something bigger during religious rituals (Charles, van Mulukom, Farias, et al., 2020), an effect which was replicated for secular ritual attendance (Charles, van Mulukom, Brown, et al., 2020), as well as in an additional lab experiment, which involved five weeks of either spiritual or secular yoga rituals (Charles et al., manuscript), with no significant differences between the two groups. Charles and colleagues suggested that the 'Broaden 


\section{PREPRINT}

and Build' hypothesis (Fredrickson, 2004, 2013; 2005; Waugh \& Fredrickson, 2006) might explain some of the results. This hypothesis proposes that positive affect (i.e., intrinsically rewarding or pleasant emotions) allows for a broadening scope of attention and behaviors to facilitate bonding with others, which then builds a social group or network. Here, we suggest that an explanation involving self-transcendence and self-transcendent emotions, in particular awe, more directly relates to a wealth of research on religious, spiritual, and artistic experiences.

\subsubsection{Self-transcendence}

Profound experiences of art or religion may be particularly personally transformative when selftranscendence takes place. Self-transcendence is what happens (1) when self-boundaries are reduced, or a focus on the self becomes less salient, and (2) when the self becomes connected to (even merging with) something bigger than oneself (whether one's surroundings, group, or even the universe), potentially via the expansion of the self beyond its boundaries (Yaden, Haidt, Hood Jr, Vago, \& Newberg, 2017).

In psychedelics research, the process of self-transcendence is often referred to as 'ego dissolution' (Nour, Evans, Nutt, \& Carhart-Harris, 2016). However, this term may confuse whether ego diminishment or ego expansion takes place (Newson, Khurana, Cazorla, \& van Mulukom, 2021): is it felt that the self is shrinking, or is it felt that the self becomes part of something bigger? We suggest here that in religious and artistic experiences particularly, it is self-expansion rather than selfdiminishment that takes place (see also the 'Broaden and Build' hypothesis, Fredrickson, 2004). In the context of awe-inspiring psychedelic trips as well as rave experiences, it has been found that selfexpansion (measured by the AWE-S subscale 'connectedness'; Yaden et al., 2018) rather than selfdiminishment (measured by the AWE-S subscale 'self-diminishment'; Yaden et al., 2018) predicted connectedness to nature or fellow ravers up to five years after the experience (Newson et al., 2021; van Mulukom, Patterson, \& van Elk, 2020). A further investigation of self-diminishment has demonstrated that there may be three dimensions to self-diminishment which may be conflated by some self-diminishment scales: perceived self-size (feeling metaphorically small), vastness relative to self, and small self-perspective (i.e., a sense of proportion about one's daily concerns; feeling one's day-to-day concerns as trivial in the grand scheme of things) (Tyson, Hornsey, \& Barlow, 2021). While the first and the last are associated with low self-esteem, perceived vastness relative to self is strongly associated with high self-esteem as well as spirituality (Tyson et al., 2021).

These unclarities regarding self-diminishment may due to a conflation of the 'self' in the selfdiminishment scale as the 'experiential self' or "I", whereas it was meant to reflect the 'rational self' or "me" (cf. Ihm, Paloutzian, van Elk, \& Schooler, 2019). We have previously argued that states of 
self-transcendence, or altered states of consciousness (ASC), crucially involve the reduction of our 'rational voice' (i.e., executive or cognitive control) and 'rational self', allowing for the experiential self to thrive (van Mulukom, 2021). James' distinction between "me" and "I" is particularly useful herein (James, 1950): $I$ as the self is the subject of experience, the person who looks through your eyes, who experiences sensations and lives in the present, whereas me as the self is a perceived object, who has a certain appearance and personal identity. In terms of self-transcendental states, then, we argued that these may involve reductions of the rational self or "me", which allows the experiential self or "I" to thrive (cf. Christy, Rivera, \& Schlegel, 2020), in a process also called 'flow' (Csikszentmihalyi, 1990) and 'absorption' (Tanya M Luhrmann, Nusbaum, \& Thisted, 2010). People may differ in their ability to achieve this, see section 6 Individual differences in subjective cognition.

This idea of a hydraulic relationship between "me" and "I" and its mechanisms is in line with theories of 'hypoegoic functioning', which argue that quietening one's conscious ego, or no longer actively attending to and thinking about the self, allows for more spontaneous, automatic, and outwardly oriented processes (Leary, Adams, \& Tate, 2006; Leary \& Guadagno, 2011). An fMRI study further demonstrates that absorption in awe-eliciting videos was associated with reduced activity in the default mode network, in particular in the posterior cingulate cortex (PCC)/precuneus and ventromedial prefrontal cortex (vmPFC) (van Elk et al., 2019), which we suggest are crucially involved in supporting the rational self or "me". Activation of the PCC/precuneus is associated with internally generated and self-referential thought, guided by pre-existing schemas (Brewer, Garrison, \& Whitfield-Gabrieli, 2013; Davey, Pujol, \& Harrison, 2016), and the vmPFC links long-term schematic knowledge with current sensory and emotional information (van Kesteren, Rijpkema, Ruiter, \& Fernández, 2010), thus grounding the rational self when activated.

\subsubsection{Awe}

While self-transcendent emotions are frequently associated with religious/spiritual experiences, the self-transcendent emotion of awe is particularly interesting as it can equally be elicited by religious as secular phenomena, such as nature, panoramic views, and works of art (Keltner \& Haidt, 2003; Shiota, Keltner, \& Mossman, 2007). Awe is a feeling of wonder experienced when facing something vaster than oneself (perceived vastness can be perceptual or conceptual), and beyond current understanding (Keltner \& Haidt, 2003). In other words, it involves two key cognitive appraisals: vastness, in the sense of psychological expansion, and need for accommodation, or a felt need to revise one's beliefs (Keltner \& Haidt, 2003). It is a meaning-making emotion which occurs during states with an exploratory style of attention (Ihm et al., 2019), and which challenges pre-existing 
meaning systems and inspires people to new perspectives and ways of thinking (Keltner \& Haidt, 2003). Importantly, awe experiences can be profoundly impactful and self-transformative experiences (Chirico \& Yaden, 2018).

People's belief systems or worldviews (including sense of identity) may be changed through this process of meaning-making and other forms of subjective cognition. The experience of selftranscendence in artistic and spiritual experiences may thus disrupt people's sense of who they are, through ego reduction or the reduction of "me", but it may also allow people reorient themselves, and thus contribute to further understandings of themselves - existential subjective knowledge such as authenticity and self-knowledge (Christy et al., 2020). Awe also has an influence on social subjective knowledge however. It has consistently been associated with feelings of connectedness (Bai et al., 2017; Newson et al., 2021; Van Cappellen \& Saroglou, 2012; van Mulukom et al., 2020) and prosocial behavior (Piff, Dietze, Feinberg, Stancato, \& Keltner, 2015; Prade \& Saroglou, 2016), effects which are typically related to the reduction of (boundaries of or emphasis on) the self (Bai et al., 2017; Piff et al., 2015). Through this awe-induced ego reduction, new perspectives related to group rather than personal identity - social subjective knowledge - can be acquired (Stellar et al., 2017).

\subsection{Belief}

By manipulating our experience imaginatively, we are able to bring our experience more sharply into focus, and find greater significance with it (Graham, 2005). Certain works of art supply us with a deeper understanding of the human condition by imaginatively illuminating our experience. The arts may be valued for their enhancement of our understanding of (human) experience, but that doesn't mean that this (i.e., art as a source of understanding) is the only reason to value art, and that art always does this, and to the same extent as other art. When the experience of the arts or religion is particularly profound, such as in self-transcendent experiences, it can become the basis for subsequent beliefs, thus contributing to motivated understandings of the world and ourselves in it. By making information salient, the arts and religion direct our attention to broad, though not scientific, truths (Bellah, 2011).

Beliefs are perhaps a prototypical example of where objective and subjective knowledge get frequently confused. For example, when a New Atheist asks a religious individual to justify their religious beliefs with evidence, they are directly confusing the two: They are treating beliefs in subjective knowledge as beliefs in objective knowledge, but religious beliefs are not of the same kind as factual beliefs (D. S. Wilson, 1995). Philosopher Neil Van Leeuwen makes the distinction between 
factual beliefs and 'religious credence' (Van Leeuwen, 2014): whereas factual beliefs are indeed vulnerable to evidence, religious credences are vulnerable to special authority, such as religious leaders or gurus. Moreover, while religious credence may be freely elaborated on, factual beliefs are independent of the context or practical setting (and lack the normative orientation that religious credence has). In other words, they have separate underlying cognitive attitudes. This distinction is further supported by empirical cross-cultural research in the United States, Ghana, Thailand, China, and Vanuatu, which demonstrates that people use the verb (or linguistic equivalent of) "to think" for factual beliefs, and "to believe" for religious credences (Van Leeuwen, Weisman, \& Luhrmann, 2020).

In the current framework, factual beliefs are beliefs about objective knowledge, whereas religious credence falls under beliefs about subjective knowledge. The two types of beliefs have, like the knowledge they convey, different functions and are appropriate in different contexts; see Contexts of objective and subjective knowledge. Problems can arise however when confusions occur: conspiracy beliefs are treated by its believers as belief in objective knowledge, leading to convictions that feel justified in the light of scientifically unsupported decisions, such as the anti-vaxx movement. However, in actuality, conspiracy beliefs are, like other pseudoscientific beliefs, epistemically suspect beliefs (Lobato, Mendoza, Sims, \& Chin, 2014), that are vulnerable to special authority, are freely elaborated on, and cannot be measured independent of practical settings (see also Boudry, 2020).

\subsection{Symbols}

So far, we have discussed feelings, experiences, and beliefs, and the non-propositional, subjective knowledge they convey. If this subjective knowledge cannot be captured by propositional descriptions, then it is less clear this knowledge is (i) memorized, and (ii) shared with others, two important functions language normally fulfils. Here, we argue that symbolic systems, such as art and religion, have evolved to fulfil these functions (van Mulukom, 2021). Indeed, it has previously been suggested that the initial utilitarian trigger of the arts was the symbolic representation of experiences (Zaidel, 2018), which we agree with and have expanded on in this article (e.g., to also include feelings and beliefs). We suggest that symbols are able to capture many meanings (which subjective cognition deduces from feelings and experiences) in an efficiently packaged, tangible, and memorable form (Alcorta, 2013), that allows for better learning and transmission of, and thinking about, these feelings, experiences, and ideas (Terrence William Deacon, 1998). 
The resulting symbolic artefacts may be material (e.g., visual artworks), but need not be (e.g., music, plays, or religious rituals). The way subjective knowledge (feelings, experiences, beliefs) are expressed symbolically is through simplification, formalization, repetition, exaggeration and elaboration of ordinary materials (Boyer \& Lienard, 2006; Dissanayake, 2009; Liénard \& Boyer, 2006; Rappaport, 1979), illuminating important aspects of the subjective knowledge and providing new perspectives (Baumberger, 2014; Graham, 2005). Artistic or religious experiences - particularly self-transcendental ones - further imbue the symbols with personal and social significance (Alcorta, 2013), and elevate the status of the symbols to the extraordinary (Dissanayake, 2009). The surges of dopamine and endorphins that accompany such experiences (Savage et al., 2020) further boost the significance, motivational force, and memorability of the resulting symbols.

The symbols are created in a way that attracts and sustains attention and interest, and that creates, shapes, and activates feelings and experiences in the symbol creator and/or witness (Dissanayake, 2009). This facilitates their mnemonic retention, social and cultural transmission, and therefore cultural selection (Atran \& Norenzayan, 2004). Here we argue that through cultural evolution, those symbols that maximize their memorability and shareability are the ones that are selected for and survive (Mesoudi, 2011).

Notably, as a result of being in a self-transcendental state with a diminished "me" or rational self, declarative memories may often be reduced (van Mulukom, 2017). However, as we have previously argued, memories of significant experiences such as those of high-arousal religious rituals need not be accurate in terms of empirically verifiable facts (i.e., objective knowledge)(van Mulukom, 2017). Declarative memory crucially relies on language to be able to convey in a descriptively accurate way what has happened, but memories of significant events should instead capture the experience and its many associations, whether music, settings, movement, sensations, or even the mystery of the ritual (Alcorta, 2013; Deeley, 2004).Thus, as Alcorta (2013) has also suggested, from a logical perspective it may be difficult to make sense of the ritual, but (sacred) symbols within the religious experience ('eternalized' in the memory of the experience) connect and condense many meanings, in a connotational and non-propositional way.

Interestingly, emotional events are more likely to be remembered than neutral events (Talarico, LaBar, \& Rubin, 2004), but emotional memories are also known to be associated with high confidence ratings relative to neutral memories, without necessarily enhancing the objective accuracy of the memories, but purely by virtue of their emotionality, which heightens the feeling of remembering (Sharot, Delgado, \& Phelps, 2004; van Mulukom, 2017; Xygalatas, 2011; Xygalatas et al., 2013). When a memory is detailed and vivid (such as memories of turning points in people's 
lives), it may continue to attract attention and evoke feelings. Moreover, the event may become tied to a long-term goal or plan of action, and inspire people to continue following that goal (i.e., motivation). Thus, memories of these events may be enduring reminders of what to attend to (i.e., what is valuable) and what to avoid, and may guide behavior in the present (Pillemer, 2001).

\section{$5 \quad$ Forms of subjective cognition}

The objective cognition system is what in folk psychology may be referred to as cognition: rational thought, analytical thinking and reasoning, comprised of mathematical and logical thinking skills, supported by working memory and conscious attention and focus (Evans, 2008; Stanovich \& West, 2000), and measured by tests such as the Cognitive Reflection Test (Frederick, 2005) and the Intelligent Quotient (IQ). Subjective cognition on the other hand comprises the cognitive processes needed to make sense of feelings, experiences, and beliefs, such as experiential thought, narrative thought, and meaning-making, respectively. These forms of subjective cognition can be thought of as hierarchical - while experiential thought makes sense of sensory experiences at a base level, meaning-making is involved with higher-order thought, such as worldviews. Here we will further examine these forms of subjective cognition.

\subsection{Experiential or intuitive thought}

Experiential or intuitive thought is a type of thinking that is automatic, fast, and subconscious, and which has also been called System/Type 1 processing (Evans, 2008; Stanovich \& West, 2000). It is typically contrasted directly with analytical thinking or System/Type 2 processing, which comprises reflective, effortful, and conscious processing (Evans, 2008; Stanovich \& West, 2000). These thinking styles are separate but not opposite types of processing (Evans, 2003), and in everyday life we likely use them continuously (Stanovich, Toplak, \& West, 2008). Previous research equated Type 2 processing with rational and logical thinking, but more recent work indicates that people also have intuitive access to logical principles (Bago \& De Neys, 2017, 2019). Instead, a more crucial distinction between the two types of processes may be that Type 1 processes are automatic but Type 2 processes are not (Stanovich, 2009). Considering this main feature of Type 1 processing automatic and subconscious processing - it is unsurprising that it has proven difficult to measure behaviorally (though see Weinberger et al., 2020 for a bottom-up approach), and typical measurements involve self-report scales focused on personality (Epstein, Pacini, Denes-Raj, \& Heier, 1996; Pacini \& Epstein, 1999) or mathematical or logical puzzles, such as the Cognitive Reflection Test (Frederick, 2005) or base-rate problems or syllogistic reasoning (Pennycook, Cheyne, Koehler, 
\& Fugelsang, 2013; Pennycook, Cheyne, Seli, Koehler, \& Fugelsang, 2012). However, personality measures are prone to social desirability biases, and the latter measures are arguably better at measuring analytical than intuitive thinking (Pennycook, Cheyne, Koehler, \& Fugelsang, 2016), and run the risk to commit a normativist fallacy (Evans \& Stanovich, 2013), since analytical responses are also the correct responses in these tasks.

More recent approaches (van Mulukom \& de Wet, forthcoming, manuscript) have however suggested that intuitive or experiential thinking can be conceptualized successfully within predictive processing theories (Clark, 2013). In this framework, intuitive thinking or intuition is considered a pre-cognitive state which occurs when an individual is fully absorbed in a situation with focused attention, and has sufficient exteroceptive and interoceptive awareness to deal with viscerosensory inputs while remaining in this flow state. Having good exteroceptive and interoceptive awareness means more accurate prior models, and together form expertise and intuition (Gigerenzer, 2007). Such an approach has proven useful in predicting intuition in acting contexts, in particular exteroception (van Mulukom \& de Wet, manuscript), and could be combined with psychophysiological measures, such as physiological skin conductance (Lufityanto, Donkin, \& Pearson, 2016).

In the context of subjective knowledge, intuitive thinking is required in particular for the processing of feelings, information at the basis of subjective knowledge. Internal and external sensory awareness contribute to correctly identify and process such input, and as such we expect greater capacities in this area to contribute to greater subjective knowledge. Previous research has already linked intuitive thinking to religiosity and spirituality (Aarnio \& Lindeman, 2005; Lindeman \& Aarnio, 2006, 2007; Pennycook et al., 2012) and engagement in the arts and associated creativity (van Mulukom \& de Wet, manuscript; Wolfradt \& Pretz, 2001).

\subsection{Narrative thought}

Psychologist Jerome Bruner (1986) has previously made a distinction between two modes of thinking, called paradigmatic thought and narrative thought. Paradigmatic thought organizes thought through abstract categorization and conceptualization, thus explaining causal relationships between sets of observable variables in 'natural' reality - what we have called objective knowledge. Narrative thought organizes thought through story devices (Singer \& Blagov, 2004), thus explaining relationships between individuals (e.g., human(like) intentions and actions and their consequences) in 'social' reality (Brendel, 2000) - what we have called subjective knowledge. Narrative thought is also considered to be the process which uses our autobiographical memory system (content) to 
support our identity (Singer \& Blagov, 2004). Through narrative processing, our biographies are unified stories about our remembered pasts, experienced presents, and anticipated futures (A. W. Geertz, 2011; McAdams, 2001; Nair, 2002; Ochs \& Capps, 1996). Thus, narrative thought supports both existential and social subjective knowledge.

Within paradigmatic and narrative thought, further processes are active. Conway and colleagues have argued that humans make sense of the world through two main human memory mechanisms: coherence and correspondence (Conway, Singer, \& Tagini, 2004). Correspondence is the drive to represent past events accurately, whereas coherence is the drive to recall events that are coherent or consistent with one's sense of self. Whereas objective cognition or paradigmatic thinking serves correspondence, it is subjective cognition or narrative thought that supports coherence. Both types of memory processing are important: We have previously argued that narrative thought and coherence are particularly important for high-arousal religious rituals (van Mulukom, 2017) and the social world more generally (van Mulukom \& de Wet, forthcoming). For example, it may allow individuals to adjust their beliefs and memories to become consistent or coherent with the perceived subjective knowledge and meaning systems of others, which in turn supports social cohesion and resulting behaviors like communication and prosocial behavior (Echterhoff, Higgins, \& Levine, 2009).

Like intuitive thought, narrative thought is harder to measure than its 'objective' counterpart. The Autobiographical Interview method (Levine, Svoboda, Hay, Winocur, \& Moscovitch, 2002) and the Autobiographical Memory Questionnaire (Rubin, Schrauf, \& Greenberg, 2003) from the memory research literature may be appropriate, which measure semantic and episodic details in memories, and phenomenological qualities of memories, respectively.

\subsection{Meaning-making}

Meaning-making is a higher level process that refers to the understanding, interpreting, and making sense of oneself and one's life, in all its aspects. Park \& Folkman (1997) have put forward the Meaning Making Model, which identifies two levels of meaning: Global meaning refers to individuals' general orienting systems and worldviews, whereas situational meaning refers to the meaning of specific instances, including the initial appraisals and possible revisions of global meanings, such as a result of illness or traumatic experiences. Indeed, whenever there is a discrepancy between the appraised meaning of a situation and an individual's global meaning, this instigates the process of meaning-making, in an attempt to reduce the discrepancy (Park, 2010). In order to do so, the meaning-making process involves either changing the appraised meaning (e.g., 
reframing; assimilation) or global meaning (e.g., one's beliefs and goals; accommodation) (Park, 2010).

Meaning-making, like personal transformativeness, is typically associated with negative events, such as traumatic childbirth (Tasuji, Reese, van Mulukom, \& Whitehouse, 2020) and coping with cancer (Park, Edmondson, Fenster, \& Blank, 2008). However, more recent research has suggested that personal transformativeness can also happen after highly intense positive experiences, such as rave parties (Newson et al., 2021). Moreover, changes in perceived meaning in life have also been observed after the experience of awe (Rivera, Vess, Hicks, \& Routledge, 2020).

Meaning in life is subjective, like the other forms of subjective knowledge, and is therefore typically measured through self-report scales, asking about meaning-making itself, such as the meaning in life questionnaire, which includes the general presence and search for meaning in life (Steger, Frazier, Oishi, \& Kaler, 2006) or asking about what gives meaning in life (content) through the ranking of common themes (Bullivant, Farias, Lanman, \& Lee, 2019) or through open-ended questions (van Mulukom et al., 2021).

\section{Individual differences in subjective cognition}

Individuals will differ in their subjective cognition and associated subjective knowledge, just as individual differences in other types of cognition exist. In particular, we suggest that the individual differences underlying subjective cognition can be found in individual differences in absorption, hypnotizability, fantasy proneness, other imaginative predispositions, intuitive thinking, divergent thinking, other creative dispositions, openness, self-transcendence, awe predisposition, spirituality, and positive schizotypy. These traits are often found to correlate with each other (e.g., Cardeña \& Terhune, 2014; Dein, 2020), with religiosity (see for an overview, Lifshitz, van Elk, \& Luhrmann, 2019) and with engagement with the arts (Panero, Goldstein, Rosenberg, Hughes, \& Winner, 2016; e.g., Wild, Kuiken, \& Schopflocher, 1995).

What might unify these individual differences or traits is the tendency to have more porous mental boundaries of the self (Taylor, 2007) ${ }^{4}$. The philosopher Charles Taylor has proposed that the modern, Western, and secular idea of the self may be thought of as a "buffered" or "bounded" self, whereby interior mental spaces are considered separate from the body and the outer world, while a more "porous" self reflects a more permeable or less emphasized boundary between the mind and the

\footnotetext{
${ }^{4} \mathrm{Cf}$. the theory of boundary structures (Hartmann, 1991) and transliminality theory (Thalbourne and Delin, 1994).
} 


\section{PREPRINT}

world and the mind and body; a conceptualization that the bounded self has shifted from, and which is more common outside of modern Western societies (Taylor, 2007).

Taylor's theory of self has been used in an empirical, cross-cultural test of variations of models of mind of varying porosity, including belief in psychic abilities and the idea that thoughts and feelings can have a direct causal impact on the world (Tanya Marie Luhrmann et al., 2021). In their methodology, they measure absorption as the main underlying individual difference, conceptualized as the experiential orientation (with immersive attention) towards one's own mind (see also Lifshitz et al., 2019). Absorption refers the propensity to become fully engaged in an activity or experience, to the extent that awareness of one's surroundings is lost (Terhune \& Jamieson, 2021) and to the extent that the imaginary involvement feels real or sensory (Lifshitz et al., 2019). Thus it involves the capacities for hyper-focus, attentional commitment, and imaginative involvement (van Mulukom \& de Wet, manuscript). Absorption is typically measured through the Tellegen Absorption Scale (Tellegen \& Atkinson, 1974) through 34 items which load onto a single factor. Thirty-four similar items load onto five subscales in the modified Tellegen Absorption Scale (Jamieson, 2005): imaginative involvement, aesthetic involvement in nature, synesthesia, altered states of consciousness, and sensed presence.

However, absorption is a complex predisposition, and recent work has pointed out that the construct is still not complete clear (Terhune \& Jamieson, 2021). Terhune and Jamieson (2021) lay out that Tellegen, the developer of the Tellegen Absorption Scale, offers three interpretations of absorption: (1) absorption in experience, or "total attention involving a full commitment of available perceptual, motoric, imaginative and ideational resources to a unified representation of the attentional object" (Tellegen \& Atkinson, 1974, p. 274), (2) surrender of an instrumental set and adoption of an experiential set, whereby the instrumental set is an "active, realistic, voluntary and relatively effortful planning, and decision making and goal directed behavior" (Tellegen, 1981, p. 222), whereas the experiential set is an "effortless, non-volitional, deep involvement with the objects of consciousness" (Tellegen, 1981, p. 222), and (3) restructuring of the phenomenal self "the capacity for marked restructuring of one's phenomenal field, especially the self and its boundaries" (Tellegen, 1992, as cited in Jamieson, 2005).

Here we suggest that absorption correlates with so many of the individual differences underlying subjective cognition because it is a measurement of the propensity of entering a state of the experiential self (see 4.2.2 Self-transcendence), which is another conceptualization of a 'porous' self: it occurs when self-boundaries are reduced or a focus on the (rational, conscious) self becomes less salient (as in self-transcendence), which allows the individual to (1) focus immersively on their 
sensory - interoceptive and exteroceptive - inputs, and/or (2) become connected to, or merging with, something bigger than oneself (such as one's group, nature, the universe, or supernatural concepts). This concept of experiential self combines several other theories laid out in the present article, and explains why the personality traits and predispositions listed above combine to support subjective cognition; both pathways imminently contribute to religious rituals and artistic experiences.

Predictive processing theories can further explain the sensory pathway of absorption, in particular how imagined sensations can come to feel real (Lifshitz et al., 2019), whereas other studies may focus on further aspects the connectedness pathway of absorption, such as empathy, bonding, and prosociality (Van Cappellen \& Saroglou, 2012; e.g., Wickramasekera \& Szlyk, 2003). Future research may also focus on whether access to, and immersion in, the experiential self can be trained (Lifshitz et al., 2019; van Mulukom \& de Wet, manuscript), thus disentangling the effects of whether people with a greater predisposition to these traits are attracted to religious rituals, meditation, and artistic experiences, and/or whether such practices can increase these capacities.

\section{Conclusions}

In this article, we have attempted to make the case that religion and art symbolize important knowledge about the human experience or condition. Such subjective knowledge about the self and others is not only valuable but in certain contexts possibly also more appropriate than objective knowledge, or facts about the physical world - it certainly has had its place in the evolution of humans, such as to provide meaning and support group cohesion. We have elucidated several forms of subjective knowledge, such as feelings, experiences, and beliefs, and the cognitive capacities that process these, such as experiential thinking, narrative processing, and meaning-making. We have demonstrated that a common state that is supportive of these processes and forms of knowledge is that of the experiential self. When self-transcendence or absorption takes place, the boundaries of the rational self become less emphasized or porous, and a state of experiential self takes its place, in which there is immersive focus on sensory input and the self can feel connected to something bigger than oneself. This state allows for new perspectives to be had and incorporated as subjective knowledge. Future research such as brain imaging may be able to further pinpoint the exact neural dynamics that underlie such self states, and the shifts between them. We conclude that in order to understand what is really important to humans and how the cognition underlying this knowledge works, we need to embrace embodiment research, and take seriously feelings, experiences, and beliefs as valid units of knowledge, and the mechanisms through which they are processed as valid forms of cognition. 


\section{Conflict of Interest}

The authors declare that the research was conducted in the absence of any commercial or financial relationships that could be construed as a potential conflict of interest.

\section{$9 \quad$ Author Contributions}

VVM did the conceptualization, VVM \& AG wrote the manuscript (original draft and review and editing).

\section{$10 \quad$ Funding}

No funding sources to be reported.

\section{Acknowledgments}

We thank Micia de Wet for her comments on parts of this manuscript which were discussed and/or presented.

\section{References}

Aarnio, K., \& Lindeman, M. (2005). Paranormal beliefs, education, and thinking styles. Personality and individual Differences, 39(7), 1227-1236.

Alcorta, C. S. (2013). Religious ritual and modes of knowing: Commentary on the cognitive resource depletion model of ritual. Religion, Brain \& Behavior, 3(1), 55-58.

Andersen, M., Schjoedt, U., Nielbo, K. L., \& Sørensen, J. (2014). Mystical experience in the lab. Method \& Theory in the Study of Religion, 26(3), 217-245.

Andresen, J., \& Forman, R. K. C. (Eds.). (2000). Cognitive models and spiritual maps: interdisciplinary explorations of religious experience. Thorverton \& Bowling Green: Imprint Academic.

Asma, S. (forthcoming). Adaptive imagination: Toward a mythopoetic cognitive science. Evolutionary Studies in Imaginative Culture.

Atran, S., \& Norenzayan, A. (2004). Religion's evolutionary landscape: Counterintuition, commitment, compassion, communion. Behavioral and Brain Sciences, 27(6), 713-730.

Baggott, M. J., Coyle, J. R., Siegrist, J. D., Garrison, K. J., Galloway, G. P., \& Mendelson, J. E. (2016). Effects of 3, 4-methylenedioxymethamphetamine on socioemotional feelings, authenticity, and autobiographical disclosure in healthy volunteers in a controlled setting. Journal of Psychopharmacology, 30(4), 378-387.

Bago, B., \& De Neys, W. (2017). Fast logic?: Examining the time course assumption of dual process theory. Cognition, 158, 90-109.

Bago, B., \& De Neys, W. (2019). The smart System 1: Evidence for the intuitive nature of correct responding on the bat-and-ball problem. Thinking \& Reasoning, 25(3), 257-299. 
Bai, Y., Maruskin, L. A., Chen, S., Gordon, A. M., Stellar, J. E., McNeil, G. D., . . Keltner, D. (2017). Awe, the diminished self, and collective engagement: universals and cultural variations in the small self. Journal of personality and social psychology, 113(2), 185-209.

Baldwin, J. R., Faulkner, S. L., Hecht, M. L., \& Lindsley, S. L. (2006). Definitions of culture. In J. R. Baldwin, S. L. Faulkner, M. L. Hecht, \& S. L. Lindsley (Eds.), Redefining Culture: Perspectives across the Disciplines (pp. 139-242). Mahwah, NJ \& London: Lawrence Erlbaum Associates, Publs.

Bar, M. (2009). The proactive brain: memory for predictions. Philosophical transactions of The Royal Society B: biological sciences, 364(1521), 1235-1243.

Barrett, L. F. (2017). How emotions are made: The secret life of the brain: Houghton Mifflin Harcourt.

Barsalou, L. W. (2009). Simulation, situated conceptualization, and prediction. Philosophical transactions of The Royal Society B: biological sciences, 364(1521), 1281-1289.

Bartlett, A. (1988). Behavioural perspectives on a Sri Lankan healing ritual. The International Journal of Social Psychiatry, 35(3), 245-251.

Baumberger, C. (2014). Art and understanding: Defence of Aesthetic Cognitivism. In C. Wagner, M. Greenlee, R. Hammwöhner, B. Körber, \& C. Wolff (Eds.), Bilder Sehen. Perspektiven Der Bildwissenschaft (pp. 62-83). Regensburg: Schnell + Steiner.

Becker, J. (2004). Deep listeners: music, emotion, and trancing. Bloomington \& Indianapolis: Indiana University Press.

Bellah, R. N. (2011). Religion in human evolution. Cambridge, MA:: Harvard University Press.

Berger, P. L., \& Luckmann, T. (1966). The social construction of reality: a treatise in the sociology of knowledge. Harmondsworth: Penguin Books Ltd.

Boudry, M. (2020). The Truth Is (Still) out There. On the Epistemology and Cultural Dynamics of Conspiracy Beliefs.

Bourguignon, E. (1968). A cross-cultural study of dissociational states. Columbus, Ohio: Research Foundation, Ohio State University.

Boyer, P., \& Lienard, P. (2006). Why ritualized behavior? Precaution systems and action parsing in developmental, pathological and cultural rituals. Behavioral and Brain Sciences, 29, 595-650.

Brendel, D. H. (2000). Philosophy of mind in the clinic: the relation between causal and meaningful explanation in psychiatry. Harvard Review of Psychiatry, 8(4), 184-191. doi:10.1007/s10508008-9318-0

Brewer, J., Garrison, K., \& Whitfield-Gabrieli, S. (2013). What about the "self" is processed in the posterior cingulate cortex? Frontiers in human neuroscience, 7, 647.

Bromberg-Martin, E. S., Matsumoto, M., \& Hikosaka, O. (2010). Dopamine in motivational control: rewarding, aversive, and alerting. Neuron, 68(5), 815-834.

Brown, S., \& Volgsten, U. (Eds.). (2006). Music and manipulation: On the social uses and social control of music. New York and Oxford: Berghahn Books.

Bruner, J. S. (1986). Actual minds, possible worlds. Cambridge, MA: Harvard University Press. 
Brust, J. C. (2007). Music as ecstasy and music as trance. In S. Coakley \& K. K. Shelemay (Eds.), Pain and Its Transformations: The Interface of Biology and Culture (pp. 195-198). Cambridge \& London: Harvard University Press.

Bullivant, S., Farias, M., Lanman, J., \& Lee, L. (2019). Understanding Unbelief: Atheists and agnostics around the world. Research report.

Cardeña, E., \& Terhune, D. B. (2014). Hypnotizability, personality traits, and the propensity to experience alterations of consciousness. Psychology of Consciousness: Theory, Research, and Practice, 1(3), 292.

Cardeña, E., \& Winkelman, M. (2011). Altering consciousness: multidisciplinary perspectives. Volume 1: History, culture, and the humanities (Vol. 1). Santa Barbara, Denver \& Oxford: Praeger.

Castillo, R. J. (1994a). Spirit possession in South Asia, dissociation or hysteria? Part 1: Theoretical background. Culture, Medicine and Psychiatry, 18, 1-21.

Castillo, R. J. (1994b). Spirit possession in South Asia, dissociation or hysteria? Part 2: Case histories. Culture, Medicine and Psychiatry, 18, 141-162.

Chalmers, A. F. (1994). What is this thing called science? An assessment of the nature and status of science and its methods (2nd ed.). Buckingham: Open University Press.

Chapin, B. L. (2008). Transforming possession: Josephine and the work of culture. Ethos, 36(2), 220245.

Charles, S. J., Farias, M., van Mulukom, V., Saraswati, A., Dein, S., Watts, F., \& Dunbar, R. I. M. (2020). Blocking mu-opioid receptors inhibits social bonding in rituals. Biology letters, 16, 20200485. doi:10.1098/rsbl.2020.0485

Charles, S. J., van Mulukom, V., Brown, J., Watts, F., Dunbar, R. I. M., \& Farias, M. (2020). United on Sunday: The effects of secular rituals on social bonding and affect. PLoS One, e0242546. doi:10.1371/journal.pone.0242546

Charles, S. J., van Mulukom, V., Farias, M., Brown, J., Delmonte, R., de Oliveira Maraldi, E., . . . Dunbar, R. I. M. (2020). Religious Rituals Increase Social Bonding and Pain Threshold. PsyArXiv. doi:10.31234/osf.io/my4hs

Charles, S. J., van Mulukom, V., Saraswati, A., Watts, F., Dunbar, R. I. M., \& Farias, M. (manuscript). Bending and Bonding: A randomized controlled trial on the sociopsychobiological effects of spiritual versus secular yoga practice.

Chirico, A., \& Yaden, D. B. (2018). Awe: a self-transcendent and sometimes transformative emotion. In H. C. Lench (Ed.), The function of emotions: When and why emotions help us (pp. 221233). Cham: Springer.

Christy, A. G., Rivera, G. N., \& Schlegel, R. J. (2020). Authenticity and the true self in religion and spirituality. In The Science of Religion, Spirituality, and Existentialism (pp. 119-139): Elsevier.

Clark, A. (2013). Whatever next? Predictive brains, situated agents, and the future of cognitive science. Behavioral and Brain Sciences, 36(3), 181-204.

Clark, A. (2015). Surfing uncertainty: Prediction, action, and the embodied mind: Oxford University Press. 
Conway, M. A., Singer, J. A., \& Tagini, A. (2004). The self and autobiographical memory: Correspondence and coherence. Social cognition, 22(5), 491-529.

Csikszentmihalyi, M. (1990). Flow. New York: Harper \& Row.

Cunningham, W. A., \& Brosch, T. (2012). Motivational salience: Amygdala tuning from traits, needs, values, and goals. Current Directions in Psychological Science, 21(1), 54-59. doi:10.1177/0963721411430832

Davey, C. G., Pujol, J., \& Harrison, B. J. (2016). Mapping the self in the brain's default mode network. Neuroimage, 132, 390-397.

Davidson, R. J., \& Irwin, W. (1999). The functional neuroanatomy of emotion and affective style. Trends in Cognitive Sciences, 3(1), 11-21.

Deacon, T. W. (1997). The symbolic species: the co-evolution of language and the human brain. London: Allen Lane The Penguin Press.

Deacon, T. W. (1998). The symbolic species: The co-evolution of language and the brain: WW Norton \& Company.

Deacon, T. W. (2003). The hierarchic logic of emergence: untangling the interdependence of evolution and self-organization. In B. H. Weber \& D. J. Depew (Eds.), Evolution and Learning: The Baldwin Effect Reconsidered (pp. 273-308). Cambridge \& London: The MIT Press.

Deeley, P. Q. (2004). The religious brain: Turning ideas into convictions. Anthropology \& Medicine, $11(3), 245-267$.

Dein, S. (2020). Transcendence, religion and social bonding. Archive for the Psychology of Religion, 42(1), 77-88.

Dervin, B. (1977). Useful theory for librarianship: Communication, not information. Drexel library quarterly, 13(3), 16-32.

Dissanayake, E. (2009). The artification hypothesis and its relevance to cognitive science, evolutionary aesthetics, and neuroaesthetics. Cognitive Semiotics, 5(fall2009), 136-191.

Donald, M. (1993). Origins of the modern mind: three stages in the evolution of culture and cognition. Cambridge \& London: Harvard University Press.

Donald, M. (2001). A mind so rare: the evolution of human consciousness. New York \& London: W. W. Norton \& Company.

Dubois, T. A. (2009). An introduction to shamanism. Cambridge: Cambridge University Press.

Durkheim, E. (2005). The dualism of human nature and its social conditions. Durkheimian Studies / Études Durkheimiennes, 11(1), 35-45.

Durkheim, É. (1912/1995). The elementary forms of religious life. Translated and with an introduction by Karen E. Fields (K. E. Fields, Trans.). New York: The Free Press.

Echterhoff, G., Higgins, E. T., \& Levine, J. M. (2009). Shared reality: Experiencing commonality with others' inner states about the world. Perspectives on Psychological Science, 4(5), 496521.

Ember, C. R., \& Carolus, C. (2017). Altered States of Consciousness. In C. R. Ember (Ed.), Explaining Human Culture. Retrieved from https://hraf.yale.edu/ehc/summaries/altered$\underline{\text { states-of-consciousness }}$ 
Epstein, S., Pacini, R., Denes-Raj, V., \& Heier, H. (1996). Individual differences in intuitiveexperiential and analytical-rational thinking styles. Journal of personality and social psychology, 71(2), 390-405.

Evans-Pritchard, E. E. (1937). Witchcraft, oracles and magic among the Azande. London: Oxford University Press.

Evans, J. S. B. (2003). In two minds: dual-process accounts of reasoning. Trends in cognitive sciences, 7(10), 454-459.

Evans, J. S. B. (2008). Dual-processing accounts of reasoning, judgment, and social cognition. Annu. Rev. Psychol., 59, 255-278.

Evans, J. S. B., \& Stanovich, K. E. (2013). Dual-process theories of higher cognition: Advancing the debate. Perspectives on psychological science, 8(3), 223-241.

Fischer, R., \& Kruekaew, J. (2019). Synchrony vs. pain in males and females: an examination of differential effects on social bonding in a naturally occurring ritual. Religion, Brain \& Behavior, 1-21. doi:10.1080/2153599X.2019.1626271

Fischer, R., \& Xygalatas, D. (2014). Extreme rituals as social technologies. Journal of Cognition and Culture, 14(5), 345-355.

Francfort, H.-P., Hamayon, R. N., \& Bahn, P. G. (Eds.). (2001). The concept of shamanism: uses and abuses. Budapest: Akadémiai Kiadó.

Frecska, E., \& Kulcsar, Z. (1989). Social bonding in the modulation of the physiology of ritual trance. Ethos, 17(1), 70-87.

Frederick, S. (2005). Cognitive reflection and decision making. Journal of Economic perspectives, 19(4), 25-42. doi:10.1257/089533005775196732

Fredrickson, B. L. (2004). The broaden-and-build theory of positive emotions. Philosophical Transactions of the Royal Society of London. Series B: Biological Sciences, 359(1449), 13671377.

Fredrickson, B. L. (2013). Positive Emotions Broaden and Build. In Advances in Experimental Social Psychology (Vol. 47, pp. 1-53): Elsevier.

Fredrickson, B. L., \& Branigan, C. (2005). Positive emotions broaden the scope of attention and thought-action repertoires. Cognition \& emotion, 19(3), 313-332. doi:10.1080/02699930441000238

Frey, S. H. (2009). Tool use, communicative gesture and cerebral asymmetries in the modern human brain. In C. Renfrew, C. Frith, \& L. Malafouris (Eds.), The sapient mind: archaeology meets neuroscience (pp. 21-31). Oxford \& New York: Oxford University Press.

Friston, K., \& Kiebel, S. (2009). Predictive coding under the free-energy principle. Philosophical transactions of The Royal Society B: biological sciences, 364(1521), 1211-1221.

Gaut, B. (2003). Art and knowledge. In J. Levinson (Ed.), The Oxford Handbook of Aesthetics (pp. 436-450).

Geertz, A. W. (2010). Brain, body and culture: a biocultural theory of religion. Method and Theory in the Study of Religion, 22(4), 304-321. 
Geertz, A. W. (2011). Religious narrative, cognition and culture: approaches and definitions. In A. W. Geertz \& J. S. Jensen (Eds.), Religious narrative, cognition and culture: image and word in the mind of narrative (pp. 9-29). Sheffield \& Oakville: Equinox Publishing, Ltd.

Geertz, A. W. (2013). Whence religion? How the brain constructs the world and what this might tell us about the origins of religion, cognition and culture. In A. W. Geertz (Ed.), Origins of Religion, Cognition and Culture (pp. 17-70). Durham: Acumen Publishing Limited.

Geertz, A. W. (in press). Introduction to cultural evolution. In Y. Lior \& J. Lane (Eds.), Routledge Handbook of Evolutionary Approaches to Religion. London and New York: Routledge.

Geertz, C. (1957/1973). Ethos, world view, and the analysis of sacred symbols. In C. Geertz (Ed.), The Interpretation of Cultures: Selected Essays (pp. 126-141). London and New York: Fontana Press and Basic Books, Inc. (Reprinted from: 1993).

Geertz, C. (1962/1973). The growth of culture and the evolution of mind. In C. Geertz (Ed.), The Interpretation of Cultures (pp. 55-83). London and New York: Fontana Press and Basic Books, Inc. (Reprinted from: 1993).

Geertz, C. (1966/1973). Religion as a cultural system. In C. Geertz (Ed.), The Interpretation of Cultures: Selected Essays (pp. 87-125). London and New York: Fontana Press and Basic Books, Inc. (Reprinted from: 1993).

Geertz, C. (1973). Thick description: toward an interpretive theory of culture. In C. Geertz (Ed.), The Interpretation of Cultures: Selected Essays (pp. 3-30). London and New York: Fontana Press and Basic Books, Inc. (Reprinted from: 1993).

Geertz, C. (1976/1983). Art as a cultural system. In C. Geertz (Ed.), Local Knowledge: Further Essays in Interpretive Anthropology (pp. 94-120). New York: Basic Books, Inc., Publishers.

Gigerenzer, G. (2007). Gut feelings: The intelligence of the unconscious: Penguin.

Goodman, F. S. (1974). Disturbances in the Apostolic Church: a trance-based upheaval in Yucatán. In F. D. Goodman, J. H. Henney, \& E. Pressel (Eds.), Trance, healing, and hallucination: three field studies in religious experience (pp. 227-364). New York et al.: John Wiley \& Sons.

Graham, G. (2005). Philosophy of the arts: An introduction to aesthetics: Routledge.

Greene, J. (2013). Moral tribes: emotion, reason, and the gap between us and them. New York: The Penguin Press.

Haidle, M. N. (2009). How to think a simple spear. In S. A. de Beaune, F. L. Coolidge, \& T. Wynn (Eds.), Cognitive Archaeology and Human Evolution (pp. 57-73). Cambridge: Cambridge University Press.

Haidle, M. N. (2012). How to think tools? A comparison of cognitive aspects in tool behavior of animals and during human evolution. Tübingen: Eberhard Karls Universität Tübingen.

Hayes, K. E. (2006). Caught in the crossfire: considering the limits of spirit possession. A Brazilian case study. Culture and Religion. An Interdisciplinary Journal, 7(2), 155-175.

Heinze, R.-I. (1991). Shamans of the 20th century. New York: Irvington Publishers, Inc.

Henrich, J. (2016). The secret of our success: how culture is driving human evolution, domesticating our species, and making us smarter. Princeton \& Oxford: Princeton University Press. 
Hobson, N. M., Schroeder, J., Risen, J. L., Xygalatas, D., \& Inzlicht, M. (2017). The psychology of rituals: an integrative review and process-based framework. Personality and Social Psychology Review, 1-25. Retrieved from doi: 10.1177/10888868317734944

Hood Jr, R. W. (1975). The construction and preliminary validation of a measure of reported mystical experience. Journal for the scientific study of religion, 29-41.

Hutchins, E. (2009). The role of cultural practices in the emergence of modern human intelligence. In C. Renfrew, C. Frith, \& L. Malafouris (Eds.), The sapient mind: archaeology meets neuroscience (pp. 119-133). Oxford \& New York: Oxford University Press.

Ihm, E. D., Paloutzian, R. F., van Elk, M., \& Schooler, J. W. (2019). Awe as a meaning-making emotion: On the evolution of awe and the origin of religions. In The Evolution of Religion, Religiosity and Theology (pp. 138-153): Routledge.

James, W. (1950). The principles of psychology, vols. I and II. New York: Dover Publications.

Jamieson, G. A. (2005). The modified Tellegen absorption scale: A clearer window on the structure and meaning of absorption. Australian Journal of Clinical and Experimental Hypnosis, 33(2), 119-139.

Kapur, S. (2003). Psychosis as a state of aberrant salience: a framework linking biology, phenomenology, and pharmacology in schizophrenia. American Journal of Psychiatry, 160(1), 13-23.

Keltner, D., \& Haidt, J. (2003). Approaching awe, a moral, spiritual, and aesthetic emotion. Cognition and emotion, 17(2), 297-314.

Koltko-Rivera, M. E. (2004). The psychology of worldviews. Review of general psychology, 8(1), 358.

Konvalinka, I., Xygalatas, D., Bulbulia, J., Schjoedt, U., Jegindø, E.-M., Wallot, S., . . Roepstorff, A. (2011). Synchronized arousal between performers and related spectators in a fire-walking ritual. Proceedings of the National Academy of Sciences, 108(20), 8514-8519.

Krauss, S. E. (2005). Research paradigms and meaning making: A primer. The qualitative report, 10(4), 758-770.

LaBar, K. S., \& Cabeza, R. (2006). Cognitive neuroscience of emotional memory. Nature Reviews Neuroscience, 7(1), 54-64.

Laland, K. N. (2017). Darwin's unfinished symphony: how culture made the human mind. Princeton and Oxford: Princeton University Press.

Leary, M. R., Adams, C. E., \& Tate, E. B. (2006). Hypo-egoic self-regulation: Exercising self-control by diminishing the influence of the self. Journal of personality, 74(6), 1803-1832.

Leary, M. R., \& Guadagno, J. (2011). The role of hypo-egoic self-processes in optimal functioning and subjective well-being. Designing positive psychology: Taking stock and moving forward, 135-146.

Levine, B., Svoboda, E., Hay, J. F., Winocur, G., \& Moscovitch, M. (2002). Aging and autobiographical memory: dissociating episodic from semantic retrieval. Psychology and aging, 17(4), 677-689. doi:10.1037//0882-7974.17.4.677

Lewis, I. M. (2003). Ecstatic religion: a study of shamanism and spirit possession (3rd ed.). London \& New York: Routledge. 
Liénard, P., \& Boyer, P. (2006). Whence collective rituals? A cultural selection model of ritualized behavior. American Anthropologist, 108(4), 814-827.

Lifshitz, M., van Elk, M., \& Luhrmann, T. M. (2019). Absorption and spiritual experience: A review of evidence and potential mechanisms. Consciousness and Cognition, 73, 102760. doi:10.1016/j.concog.2019.05.008

Lindeman, M., \& Aarnio, K. (2006). Paranormal beliefs: Their dimensionality and correlates. European Journal of Personality, 20(7), 585-602.

Lindeman, M., \& Aarnio, K. (2007). Superstitious, magical, and paranormal beliefs: An integrative model. Journal of research in Personality, 41(4), 731-744.

Lobato, E. J., Mendoza, J., Sims, V., \& Chin, M. (2014). Examining the relationship between conspiracy theories, paranormal beliefs, and pseudoscience acceptance among a university population. Applied Cognitive Psychology, 28(5), 617-625. doi:10.1002/acp.3042

Lufityanto, G., Donkin, C., \& Pearson, J. (2016). Measuring intuition: nonconscious emotional information boosts decision accuracy and confidence. Psychological science, 27(5), 622-634.

Luhrmann, T. M., Nusbaum, H., \& Thisted, R. (2010). The absorption hypothesis: Learning to hear God in evangelical Christianity. American Anthropologist, 112(1), 66-78.

Luhrmann, T. M., Weisman, K., Aulino, F., Brahinsky, J. D., Dulin, J. C., Dzokoto, V. A., . . RossZehnder, N. (2021). Sensing the presence of gods and spirits across cultures and faiths. Proceedings of the National Academy of Sciences, 118(5). doi:10.1073/pnas.2016649118

Maij, D. L., \& van Elk, M. (2018). Getting absorbed in experimentally induced extraordinary experiences: Effects of placebo brain stimulation on agency detection. Consciousness and Cognition, 66, 1-16.

Malafouris, L. (2004). The cognitive basis of material engagement: where brain, body and culture conflate. In E. DeMarrais, C. Gosden, \& C. Renfrew (Eds.), Rethinking Materiality: The Engagement of Mind with the Material World (pp. 53-62). Cambridge: McDonald Institute for Archaeological Research.

Malafouris, L. (2008). Between brains, bodies and things: tectonoetic awareness and the extended self. Philosophical Transactions of the Royal Society B. Biological Sciences, 363, 1993-2002.

Malafouris, L. (2010). The brain-artefact interface (BAI): a challenge for archaeology and cultural neuroscience. Social cognitive and affective neuroscience, 5(2-3), 264-273.

Maryanski, A. (1993). The elementary forms of the first proto-human society: an ecological/social network approache. Advances in Human Evolution, 2, 215-241.

Maryanski, A. (1995). African ape social networks: a blueprint for reconstructing early hominid social structure. In J. Steele \& S. Shennan (Eds.), Archaeology of Human Ancestry (pp. 6790). London: Routledge.

Maryanski, A. (2013). The secret of the hominin mind: an evolutionary story. In D. D. Franks \& J. H. Turner (Eds.), Handbook of Neurosociology (pp. 257-287). New York, Dordrecht, Heidelberg, London: Springer.

Maryanski, A. (2018). Émile Durkheim and the birth of the gods: Clans, incest, totems, phratries, hordes, mana, taboos, corroborees, sodalities, menstrual blood, apes, churingas, cairns, and other mysterious things. New York: Routledge. 
Mauss, M., \& Durkheim, É. (1913). Review of Frazer, Totemism and Exogamy and Durkheim, Les formes élémentaires de la vie religieuse: le système totémique en Australie. Année sociologique, 12, 94-98.

McAdams, D. P. (2001). The psychology of life stories. Review of general psychology, 5(2), 100122.

Mesoudi, A. (2011). Cultural evolution: how Darwinian theory can explain human culture and synthesize the social sciences In. Chicago: University of Chicago Press.

Miller, W. W. (2005). Dynamogénique and Élémentaire. Durkheimian Studies, 11(1), 18-32.

Mishara, A. L., \& Fusar-Poli, P. (2013). The phenomenology and neurobiology of delusion formation during psychosis onset: Jaspers, Truman symptoms, and aberrant salience. Schizophrenia bulletin, 39(2), 278-286.

Nair, R. B. (2002). Narrative gravity: conversation, cognition, culture. Oxford \& New Delhi: Oxford University Press.

Newson, M., Khurana, R., Cazorla, F., \& van Mulukom, V. (2021). 'I get high with a little help from my friends' - How raves can invoke identity fusion and lasting co-operation via transformative experiences. Frontiers in Psychology, 12, 719596. doi:10.3389/fpsyg.2021.719596

Nin, A. s. (1968). The Novel of the Future. New York: Collier Books.

Nour, M. M., Evans, L., Nutt, D., \& Carhart-Harris, R. L. (2016). Ego-dissolution and psychedelics: validation of the ego-dissolution inventory (EDI). Frontiers in human neuroscience, 10, 269.

Ochs, E., \& Capps, L. (1996). Narrating the self. Annual Review of Anthropology, 25, 19-43.

Ovsepyan, M. (2019). Reimagining the Imaginaries: Towards a Biocultural Theory of (Non) religion. Journal for the Cognitive Science of Religion, 5(1), 85-99.

Pacini, R., \& Epstein, S. (1999). The relation of rational and experiential information processing styles to personality, basic beliefs, and the ratio-bias phenomenon. Journal of personality and social psychology, 76(6), 972-987.

Panero, M. E., Goldstein, T. R., Rosenberg, R., Hughes, H., \& Winner, E. (2016). Do actors possess traits associated with high hypnotizability? Psychology of Aesthetics, Creativity, and the Arts, 10(2), 233-239.

Park, C. L. (2010). Making sense of the meaning literature: an integrative review of meaning making and its effects on adjustment to stressful life events. Psychological bulletin, 136(2), 257-301.

Park, C. L., Edmondson, D., Fenster, J. R., \& Blank, T. O. (2008). Meaning making and psychological adjustment following cancer: the mediating roles of growth, life meaning, and restored just-world beliefs. Journal of Consulting and Clinical Psychology, 76(5), 863-875.

Park, C. L., \& Folkman, S. (1997). Meaning in the context of stress and coping. Review of general psychology, 1(2), 115-144.

Pearce, E., Launay, J., \& Dunbar, R. I. (2015). The ice-breaker effect: singing mediates fast social bonding. Royal Society open science, 2(10), 150221.

Pearce, E., Launay, J., van Duijn, M., Rotkirch, A., David-Barrett, T., \& Dunbar, R. I. (2016). Singing together or apart: The effect of competitive and cooperative singing on social 
bonding within and between sub-groups of a university Fraternity. Psychology of music, 44(6), 1255-1273.

Pennycook, G., Cheyne, J. A., Koehler, D. J., \& Fugelsang, J. A. (2013). Belief bias during reasoning among religious believers and skeptics. Psychonomic Bulletin \& Review, 20(4), 806-811.

Pennycook, G., Cheyne, J. A., Koehler, D. J., \& Fugelsang, J. A. (2016). Is the cognitive reflection test a measure of both reflection and intuition? Behavior Research Methods, 48(1), 341-348.

Pennycook, G., Cheyne, J. A., Seli, P., Koehler, D. J., \& Fugelsang, J. A. (2012). Analytic cognitive style predicts religious and paranormal belief. Cognition, 123(3), 335-346.

Piff, P. K., Dietze, P., Feinberg, M., Stancato, D. M., \& Keltner, D. (2015). Awe, the small self, and prosocial behavior. Journal of personality and social psychology, 108(6), 883-899.

Pillemer, D. B. (2001). Momentous events and the life story. Review of general psychology, 5(2), 123-134.

Power, E. A. (2018). Collective ritual and social support networks in rural South India. Proceedings of the Royal Society B: Biological Sciences, 285(1879), 20180023.

Prade, C., \& Saroglou, V. (2016). Awe's effects on generosity and helping. The Journal of Positive Psychology, 11(5), 522-530.

Putnam, H. W. (Ed.) (1992). Realism with a human face. Cambridge \& London: Harvard University Press.

Rappaport, R. A. (1979). Ecology, meaning, and religion. Berkeley: North Atlantic Books.

Renfrew, C. (1998). Mind and matter: cognitive archaeology and external symbolic storage. In C.

Renfrew \& C. Scarre (Eds.), Cognition and Material Culture: the Archaeology of Symbolic Storage (pp. 1-6). Cambridge: McDonald Institute for Archaeological Research.

Renfrew, C., Frith, C., \& Malafouris, L. (Eds.). (2009). The sapient mind: archaeology meets neuroscience. Oxford \& New York: Oxford University Press.

Rivera, G. N., Vess, M., Hicks, J. A., \& Routledge, C. (2020). Awe and meaning: Elucidating complex effects of awe experiences on meaning in life. European Journal of Social Psychology, 50(2), 392-405.

Rolls, E. T. (2000). Precis of the brain and emotion. Behavioral and Brain Sciences, 23(2), 177-191.

Rubin, D. C., Schrauf, R. W., \& Greenberg, D. L. (2003). Belief and recollection of autobiographical memories. Memory \& cognition, 31(6), 887-901.

Rutjens, B. T., \& Preston, J. L. (2020). Science and religion: a rocky relationship shaped by shared psychological functions. In K. I. Vail \& C. Routledge (Eds.), The science of religion, spirituality, and existentialism (pp. 373-385). Cambridge, MA: Academic Press.

Savage, P. E., Loui, P., Tarr, B., Schachner, A., Glowacki, L., Mithen, S., \& Fitch, W. T. (2020). Music as a coevolved system for social bonding. Behavioral and Brain Sciences, 1-36.

Schjoedt, U., \& Jensen, J. S. (2018). Depletion and deprivation: social functional pathways to a shared metacognition. In J. Proust \& M. Fortier (Eds.), Metacognitive Diversity: An Interdisciplinary Approach (pp. 319-342). Oxford: Oxford University Press.

Schjoedt, U., Sørensen, J., Nielbo, K. L., Xygalatas, D., Mitkidis, P., \& Bulbulia, J. (2013a). Cognitive resource depletion in religious interactions. Religion, Brain \& Behavior, 3(1), 3955. 
Schjoedt, U., Sørensen, J., Nielbo, K. L., Xygalatas, D., Mitkidis, P., \& Bulbulia, J. (2013b). The resource model and the principle of predictive coding: A framework for analyzing proximate effects of ritual. Religion, Brain \& Behavior, 3(1), 79-86. doi:10.1080/2153599X.2012.745447

Searle, J. R. (1995). The construction of social reality. Harmondsworth: Penguin Books Ltd.

Searle, J. R. (1998). Mind, language and society: philosophy in the real world. New York: Basic Books.

Shanton, K., \& Goldman, A. (2010). Simulation theory. Wiley Interdisciplinary Reviews: Cognitive Science, 1(4), 527-538.

Sharot, T., Delgado, M. R., \& Phelps, E. A. (2004). How emotion enhances the feeling of remembering. Nature neuroscience, 7(12), 1376-1380.

Shiota, M. N., Keltner, D., \& Mossman, A. (2007). The nature of awe: Elicitors, appraisals, and effects on self-concept. Cognition and emotion, 21(5), 944-963.

Siikala, A.-L. (1987). The rite technique of the Siberian shaman. Helsinki: Academia Scientiarum Fennica.

Singer, J. A., \& Blagov, P. (2004). The Integrative Function of Narrative Processing: Autobiographical Memory, Self-Defining Memories, and the Life Story of Identity. In D. R. Beike, J. M. Lampinen, \& D. A. Behrend (Eds.), The self and memory (pp. 117-138). New York: Psychology Press.

Spuhler, J. N. (Ed.) (1959). The evolution of man's capacity for culture. Detroit: Wayne State University Press.

Stanovich, K. E. (2009). Distinguishing the reflective, algorithmic, and autonomous minds: Is it time for a tri-process theory? In J. S. B. Evans \& K. Frankish (Eds.), In two minds: Dual processes and beyond (pp. 55-88). Oxford, England: Oxford University Press.

Stanovich, K. E., Toplak, M. E., \& West, R. F. (2008). The development of rational thought: A taxonomy of heuristics and biases. In Advances in child development and behavior (Vol. 36, pp. 251-285): Elsevier.

Stanovich, K. E., \& West, R. F. (2000). Advancing the rationality debate. Behavioral and Brain Sciences, 23(05), 701-717.

Stark, R. (2009). Discovering God: The origins of the great religions and the evolution of belief: Harper Collins.

Steger, M. F., Frazier, P., Oishi, S., \& Kaler, M. (2006). The meaning in life questionnaire: assessing the presence of and search for meaning in life. Journal of counseling psychology, 53(1), 8093.

Stellar, J. E., Gordon, A. M., Piff, P. K., Cordaro, D., Anderson, C. L., Bai, Y., . . Keltner, D. (2017). Self-transcendent emotions and their social functions: Compassion, gratitude, and awe bind us to others through prosociality. Emotion Review, 9(3), 200-207.

Suryani, L. K., \& Jensen, G. B. (1995). Trance and possession in Bali: a window on Western multiple personality, possession disorder and suicide. Oxford: Oxford University Press.

Talarico, J. M., LaBar, K. S., \& Rubin, D. C. (2004). Emotional intensity predicts autobiographical memory experience. Memory \& cognition, 32(7), 1118-1132. 
Tarr, B., Launay, J., Cohen, E., \& Dunbar, R. (2015). Synchrony and exertion during dance independently raise pain threshold and encourage social bonding. Biology letters, 11(10), 20150767.

Tarr, B., Launay, J., \& Dunbar, R. I. (2016). Silent disco: dancing in synchrony leads to elevated pain thresholds and social closeness. Evolution and Human Behavior, 37(5), 343-349.

Tasuji, T., Reese, E., van Mulukom, V., \& Whitehouse, H. (2020). Band of mothers: Childbirth as a female bonding experience. PLoS One, 15(10), e0240175.

Taves, A., Asprem, E., \& Ihm, E. (2018). Psychology, meaning making, and the study of worldviews: Beyond religion and non-religion. Psychology of Religion and Spirituality, 10(3), 207.

Taylor, C. (2007). A secular age. Cambridge, MA: Harvard university press.

Tellegen, A. (1981). Practicing the two disciplines for relaxation and enlightenment: Comment on "Role of the feedback signal in electromyograph biofeedback: the relevance of attention" by Qualls and Sheehan. Journal of Experimental Psychology: General, 110, 217-226.

Tellegen, A., \& Atkinson, G. (1974). Openness to absorbing and self-altering experiences (" absorption"), a trait related to hypnotic susceptibility. Journal of abnormal psychology, 83(3), 268-277.

Terhune, D. B., \& Jamieson, G. A. (2021). Hallucinations and the meaning and structure of absorption. Proceedings of the National Academy of Sciences, 118(32).

Thalbourne, M. A., \& Delin, P. S. (1994). A common thread underlying belief in the paranormal, creative personality, mystical experience and psychopathology. Journal of Parapsychology, 58(1), 3-38.

Turner, J. H. (2000). On the origins of human emotions: a sociological inquiry into the evolution of human affect. Stanford: Stanford University Press.

Turner, J. H. (2015). The evolution of human emotions. In J. E. Stets \& J. H. Turner (Eds.), Handbook of the Sociology of Emotions: Volume II (pp. 11-31). Dordrecht: Springer Science and Business Media.

Turner, J. H. (2019). Religion as an artifact of selection pressures to make hominins more social. In A. K. Petersen, I. S. Gilhus, L. H. Martin, J. S. Jensen, \& J. Sørensen (Eds.), Evolution, Cognition, and the History of Religions: A New Synthesis. Festschrift in Honour of Armin W. Geertz (pp. 190-205). Leiden and Boston: Brill.

Turner, J. H., \& Maryanski, A. (2008). On the origin of societies by natural selection. Boulder \& London: Paradigm Publishers.

Turner, J. H., Maryanski, A., Petersen, A. K., \& Geertz, A. W. (2018). The emergence and evolution of religion: by means of natural selection. New York \& London: Routledge.

Turner, J. H., \& Stets, J. E. (2009). The sociology of emotions. Cambridge: Cambridge University Press.

Turner, V. (1967). Betwixt and between: the liminal period in Rites de Passage. In The forest of symbols: aspects of Ndembu ritual (pp. 93-111). Ithaca \& London: Cornell University Press.

Turner, V. (1969). The ritual process: structure and anti-structure. Harmondsworth: Penguin Books, Ltd. 
Turner, V. (1985a). Epilogue: are there universals of performance in myth, ritual, and drama? In E. L. B. Turner (Ed.), On the Edge of the Bush: Anthropology as Experience (pp. 291-301). Tucson: The University of Arizona Press.

Turner, V. (1985b). Process, system, and symbol: a new anthropological synthesis. In E. L. B. Turner (Ed.), On the Edge of the Bush: Anthropology as Experience (pp. 151-173). Tucson: The University of Arizona Press.

Turner, V. W. (1968). Schism and continuity in an African society: a study of Ndembu village life. Manchester: Manchester University Press.

Tyson, C., Hornsey, M. J., \& Barlow, F. K. (2021). What does it mean to feel small? Three dimensions of the small self. Self and Identity, 1-19.

Van Cappellen, P., \& Saroglou, V. (2012). Awe activates religious and spiritual feelings and behavioral intentions. Psychology of Religion and Spirituality, 4(3), 223-236.

van Elk, M. (2014). An EEG study on the effects of induced spiritual experiences on somatosensory processing and sensory suppression. Journal for the Cognitive Science of Religion, 2(2), 121157.

van Elk, M., van der Zwaag, W., Arciniegas, A., van Schie, H. T., \& Sauter, D. (2019). Reduced default mode network activity during the experience of awe. Human brain mapping, 40(12), 3561-3574.

van Gennep, A. (1909/1960). Rites of passage (M. B. Vizedom \& G. L. Caffee, Trans.). Chicago: University of Chicago Press.

van Kesteren, M. T., Rijpkema, M., Ruiter, D. J., \& Fernández, G. (2010). Retrieval of associative information congruent with prior knowledge is related to increased medial prefrontal activity and connectivity. Journal of neuroscience, 30(47), 15888-15894.

Van Leeuwen, N. (2014). Religious credence is not factual belief. Cognition, 133(3), 698-715.

Van Leeuwen, N., Weisman, K., \& Luhrmann, T. M. (2020). "Think" and" believe" across cultures: A shared folk distinction between two cognitive attitudes in the US, Ghana, Thailand, China, and Vanuatu. Paper presented at the CogSci.

van Mulukom, V. (2017). Remembering religious rituals: autobiographical memories of high-arousal religious rituals considered from a narrative processing perspective. Religion, Brain \& Behavior, 7(3), 191-205. doi:10.1080/2153599X.2016.1232304

van Mulukom, V. (2019). The cognitive science of imagination and religion. Journal for the Cognitive Science of Religion, 5(1), 5-20. doi:10.1558/jcsr.39503

van Mulukom, V. (2020). The evolution of imagination and fiction through generativity and narrative. In J. Carroll, M. Clasen, \& E. Jonsson (Eds.), Evolutionary Perspectives on Imaginative Culture (pp. 53-70). Cham: Springer.

van Mulukom, V. (2021). The evolution of music as artistic cultural innovation expressing intuitive thought symbolically. Behavioral and Brain Sciences, 44, e019. doi:10.1017/S0140525X20001260

van Mulukom, V., \& Clasen, M. (2021). The evolutionary functions of imagination and fiction and how they may contribute to psychological wellbeing during a pandemic. PsyArXiv.

doi:10.31234/osf.io/wj4zg 
van Mulukom, V., \& de Wet, M. (forthcoming). The Importance of Narrative and Intuitive Thought in Navigating our Realities. Evolutionary Studies in Imaginative Culture.

van Mulukom, V., \& de Wet, M. (manuscript). Such stuff as dreams are made on: Acting intuition and imagination are supported by interoceptive, exteroceptive, and immersive abilities

van Mulukom, V., \& Lang, M. (2021). Religious experiences are interpreted through priors from cultural frameworks supported by imaginative capacity rather than special cognition. Journal for the Cognitive Science of Religion, 7(1), 39-53.

van Mulukom, V., Patterson, R., \& van Elk, M. (2020). Broadening Your Mind to Include Others: The relationship between serotonergic psychedelic experiences and maladaptive narcissism. Psychopharmacology, 237, 2725-2737.

van Mulukom, V., Turpin, H., Purzycki, B. G., Haimila, R., Bendixen, T., Klocová, E. K., \& Farias, M. (2021). What do non-religious non-believers believe in? Secular worldviews around the world. PsyArXiv. doi:10.31234/osf.io/gtcem

Waugh, C. E., \& Fredrickson, B. L. (2006). Nice to know you: Positive emotions, self-other overlap, and complex understanding in the formation of a new relationship. The Journal of Positive Psychology, 1(2), 93-106.

Weinberger, A. B., Gallagher, N. M., Warren, Z. J., English, G. A., Moghaddam, F. M., \& Green, A. E. (2020). Implicit pattern learning predicts individual differences in belief in God in the United States and Afghanistan. Nature communications, 11(1), 1-12.

Wickramasekera, I. E., \& Szlyk, J. P. (2003). Could empathy be a predictor of hypnotic ability? International Journal of Clinical and Experimental Hypnosis, 51(4), 390-399.

Wild, T. C., Kuiken, D., \& Schopflocher, D. (1995). The role of absorption in experiential involvement. Journal of personality and social psychology, 69(3), 569-579.

Wilson, D. S. (1995). Language as a community of interacting belief systems: A case study involving conduct toward self and others. Biology and Philosophy, 10(1), 77-97.

Wilson, M. (2010). The re-tooled mind: how culture re-engineers cognition. Social cognitive and affective neuroscience, 5(2-3), 180-187.

Winkelman, M. J. (1986). Trance states: A theoretical model and cross-cultural analysis. Ethos, 14(2), 174-203.

Winkelman, M. J. (1992). Shamans, priests and witches: a cross-cultural study of magico-religious practitioners. Tempe: Arizona State University.

Wise, R. A. (2004). Dopamine, learning and motivation. Nature Reviews Neuroscience, 5(6), 483494.

Wolfradt, U., \& Pretz, J. E. (2001). Individual differences in creativity: Personality, story writing, and hobbies. European journal of personality, 15(4), 297-310.

Xygalatas, D. (2008). Firewalking and the brain: the physiology of high-arousal rituals. In J. Bulbulia, R. Sosis, E. Harris, R. Genet, C. Genet, \& K. Wyman (Eds.), The Evolution of Religion: Studies, Theories, \& Critiques (pp. 189-195). Santa Margarita: Collins Foundation Press.

Xygalatas, D. (2011). Firewalking in the Balkans: 'high-arousal' rituals and memory. In I. Czachesz \& T. Biró (Eds.), Religion and Cognition through the Ages (pp. 193-209). Leuven: Peeters. 
Xygalatas, D. (2014). The biosocial basis of collective effervescence: An experimental anthropological study of a fire-walking ritual. Fieldwork in Religion, 9(1), 53-67.

Xygalatas, D., Konvalinka, I., Roepstorff, A., \& Bulbulia, J. (2011). Quantifying collective effervescence: Heart-rate dynamics at a fire- walking ritual. Communicative \& Integrative Biology, 4(6), 735-738.

Xygalatas, D., Schjoedt, U., Bulbulia, J., Konvalinka, I., Jegindø, E.-M., Reddish, P., . . Roepstorff, A. (2013). Autobiographical memory in a fire-walking ritual. Journal of Cognition and Culture, 13(1), 1-16.

Yaden, D. B., Haidt, J., Hood Jr, R. W., Vago, D. R., \& Newberg, A. B. (2017). The varieties of selftranscendent experience. Review of general psychology, 21(2), 143-160.

Yaden, D. B., Kaufman, S. B., Hyde, E., Chirico, A., Gaggioli, A., Zhang, J. W., \& Keltner, D. (2018). The development of the Awe Experience Scale (AWE-S): A multifactorial measure for a complex emotion. The Journal of Positive Psychology, 1-15.

Yaden, D. B., Le Nguyen, K. D., Kern, M. L., Wintering, N. A., Eichstaedt, J. C., Schwartz, H. A., . . . Hood Jr, R. W. (2017). The noetic quality: A multimethod exploratory study. Psychology of Consciousness: Theory, Research, and Practice, 4(1), 54-62.

Zaidel, D. W. (2018). Culture and art: Importance of art practice, not aesthetics, to early human culture. In J. F. Christensen \& A. Gomila (Eds.), Progress in Brain Research (Vol. 237, pp. 25-40): Elsevier. 